\title{
Characterisation of unessential genes required for survival under conditions of DNA stress
}

\author{
Hassan Ahmed Ezzat ${ }^{*}$ and Clive Price
}

\begin{abstract}
Background: Genomic instability is a hallmark of cancer. Cancer progression depends on the development and amplification of mutations that alter the cellular response to threats to the genome. This can lead to DNA replication stress and the potential loss of genetic integrity of the newly formed cells. This study utilised fission yeast to map the interactions occurring in some of the most crucial pathways in both DNA replication and checkpoint monitoring involving Rad4, the Schizosaccharomyces pombe (S. pombe) TopBP1 homologue. We have modelled conditions of replication stress in the genetically tractable fission yeast, S. pombe using the hypomorphic rad4-116 allele. Synthetic genetic analysis was used to identify processes required for cell survival under conditions of DNA replication stress. With the aim of mapping the genetic interactions of rad4 and its mutant allele, rad4-116, several genes that could have an interaction with rad4 during replication stress have emerged as attractive.

Results: Interactions with genes involved in chromatin remodelling, such as hip 1, and replication fork stalling resolution, such as mrcl, swil and swi3 were explored and confirmed. The interactions of Rad4 with each of the genes provided separate and distinct tumour formation pathways, as evident in the synthetically lethal interactions. Even within the same complex, rad4-116 double mutants behaved differently proving that Rad4 interacts at different levels and functions with the same proteins.

Conclusion: Results from this study provide a novel view of the rad4 interactions, the association of Rad4 with the replisome. The study also provides the groundwork on a theoretical and practical level for the exploration and separation of interactions of TopBP1 with the histone chaperone family and the replisome.
\end{abstract}

Keywords: Schizosaccharomyces pombe, TopBP1, Eukaryotic DNA replication, DNA Fork Stalling

\section{Background}

Across all cell types, from the simplest bacteria to the most complex multicellular organisms, precise coordination of DNA replication with chromosome segregation during the cell division cycle is essential to ensure that both daughter cells inherit a complete and intact complement of genetic material. The relatively large genomes of eukaryotic cells are replicated from multiple replication origins on multiple chromosomes. DNA replication per se requires the activity of a number of DNA

* Correspondence: hassan_serapeace@hotmail.com

Division of Biomedical and Life Sciences, Faculty of Health and Medicine, Lancaster University, Lancaster, UK

\section{Springer Open}

polymerases, the initial activity of which is confined to these origins [1]. The cell division cycle process has been linked to a wide variety of physiologic processes such as embryonic development and cell growth and pathologic processes such as cancer and Alzheimer's disease [2]. This occurs as errors or defects in genes which play a role in DNA replication, DNA repair, or checkpoint response have been highlighted to play a key role in the predisposition to cancer $[3,4]$. As a regular event occurring in cancer, replication stress can be identified as the stalling or slowing of replication forks causing any alteration in the regular replication process such as the unwinding of DNA through decoupling of replicative

(c) The Author(s). 2020 Open Access This article is licensed under a Creative Commons Attribution 4.0 International License, which permits use, sharing, adaptation, distribution and reproduction in any medium or format, as long as you give appropriate credit to the original author(s) and the source, provide a link to the Creative Commons licence, and indicate if changes were made. The images or other third party material in this article are included in the article's Creative Commons licence, unless indicated otherwise in a credit line to the material. If material is not included in the article's Creative Commons licence and your intended use is not permitted by statutory regulation or exceeds the permitted use, you will need to obtain permission directly from the copyright holder. To view a copy of this licence, visit http://creativecommons.org/licenses/by/4.0/. 
helicases and polymerases [5]. It can be viewed as an important event that is common across all cancer types to the point that it has been proposed as a hallmark of cancer [6].

To be able to pinpoint the origins, origins are bound by the origin recognition complex (ORC) which is a heterohexamer constituted of subunits named ORC 1, 2, 3, 45 and 6 with ORC1 binding being an early event in the regulation of replication $[7,8]$. ORC1 and ORC6 bind relatively loosely to the origin while ORCs 2 to 5 bind strongly to the origin. The ORC complex then recruits CDC6 and CDT1 to form the PreRC which recruits the heterohexamer minichromosome maintenance complex (MCM). MCM is composed of 6 subunits MCM2-7 and promotes the recruitment of another MCM2-7 complex forming a double hexamer of MCM2-7s on chromatin during the process of replication licensing [9-11]. Then, cyclin E-bound CDK2 and DDK promote the recruitment of the CDC45-MCM2-7-GINS complex (CMG) which acts to separate the MCM2-7 hexamers, thereby, activating their helicase activity [12]. These structures are called pre-initiation complexes (PreICs), at which the replicative polymerases are now recruited. The replicative polymerase pol $\alpha$ synthesises short strands of RNA that prime DNA replication of the leading strand by the processivity factor PCNA bound pol $\varepsilon$ and the lagging strand by pol $\delta$ [13]. Polymerase $\varepsilon$ has been shown to be essential for helicase activation and remains associated with the CMG complex [14]. Interestingly, there is recent evidence that pol $\delta$ is required for the proper balance of the leading and the lagging strand synthesis coupled with the hypothesis that it may have played an important role in DNA synthesis of the leading strand when the cells exhibit replication stress [15]. Using purified S.cerevisiae replication proteins, it was discovered that the basic requirement for DNA replication initiation involves 16 replication factors alongside cyclin A-CDK2 and DDK phosphorylation [16]. It is to be noted that that study involved using replisome protein Mrc1 and Csm3/Tof1, to stabilise the activity of Mrc1 in vitro, to be able to achieve replication rates similar to those observed in vivo [16].

In normal cells, when an event leading to replication stress occurs, the DNA damage response is activated leading to the arrest of the cell cycle until DNA can be effectively repaired or the marking of cells for apoptosis. The marking of cells for apoptosis occurs to provide an effective way to prevent cells from progressing further into tumourigenesis. To protect the information encrypted within the DNA against damage and preserve genomic stability, eukaryotic cells have evolved the DNA structure checkpoint signalling pathways which are often referred to as the DNA-damage response (DDR) [17]. During replication stress, long stretches of ssDNA occur due to the uncoupling and dissociation of replicative polymerases and helicases [18]. This causes ssDNA to become coated with RPA to facilitate the recruitment of ataxia telangiectasia and Rad3-related protein (ATR) which phosphorylates various proteins involved in cell cycle arrest $[5,19]$. The DNA damage response has been utilised by tumour cells to survive replicative stress by using the same proteins in ATR and CHK1. This occurs as the activation of ATR and CHK1 prevents the exposure of longer length ssDNA and thus prevents the collapse of replication forks. It has been confirmed that the activity of both ATR and CHK1 is required to stabilise DNA with RPA, thereby, preventing the collapse of replication fork [20, 21].

During a typical process of chromosome replication, replication forks can pause briefly when faced with sites where non-nucleosomal proteins are bound tightly. Any failure to stabilise these stalled replication forks can result in their collapse and thus, the monitoring of ongoing forks is essential for maintaining the integrity of the genome. Stalled replication forks need to be resolved in a swift manner by the cellular surveillance systems to be able to prevent the forks from collapsing and eventually complete the replication process $[22,23]$. In $S$. pombe, the DNA structure checkpoints can be categorised into the DNA replication checkpoint and the DNA damage checkpoint. The major difference is that the DNA replication checkpoint prevents DNA damage in response to replication stress during S-phase, whilst the DNA damage checkpoint detects and resolves DNA damage before entry into mitosis [24]. An essential checkpoint response involves the arrest of the cell cycle by temporarily reducing CDK levels using CDK inhibitors and Cdc25 activity [24, 25]. In S. pombe, the DNA replication checkpoint depends primarily on the $\operatorname{Rad} 3 /$ Cds1 cascade pathway. This occurs as the replisome unwinds DNA downstream of the stalled replication fork to expose ssDNA structures to allow the loading and activation of the phosphatidylinositol 3-kinase-related protein kinase $\operatorname{Rad} 3$ in complex with $\operatorname{Rad} 26$ to the stalled replication fork areas [26-28]. Another independent reaction also occurs as the heterotrimeric Rad9Rad1-Hus1 clamp is loaded using the Rfc2-5-Rad17-like loading complex to be able to fully activate $\operatorname{Rad} 3$ and Cds1 [29]. Cds1 is activated by a phosphorylation network composed of one basal and three parallel phosphorylation steps mediated by Rad3, Mrc1 and Rad9 [30, 31]. Another response is the DNA replication checkpoint transcriptional response, which includes the maintenance of the MluI cell cycle box (MCB) binding factor (MBF)-dependent G1/S transcriptional network [32]. This eventually causes the activation of MBF-dependent transcription which is essential for the survival of cells in response to replicative stress [33].

It was identified that the Rad4 is conserved across eukaryotes and that it is an essential gene as multicellular 
organism cells exhibit lethality when its function is disrupted $[34,35]$. Expression of the cut mutant phenotype requires the viable function of several $M$ phase regulators. This occurs due to the role of Rad4 in checkpoint control pathway and that role was characterised and developed by previous studies [36-41]. Fission yeast cut mutations disrupt coordination between $\mathrm{M}$ phase and cytokinesis, and cell division takes place in the absence of normal nuclear division [42]. There are approximately 20 cut genes known; however, DNA synthesis is not inhibited in any cut mutants except cut5..$^{39,42}$ The rad4116 allele mimics conditions of replication stress in the absence of checkpoint function which makes it an attractive allele to utilise to study the genetic interactions of rad4 [43].

During the $\mathrm{S}$ phase, nucleosomes are removed before the arrival of the replication machinery on the replication fork and then, nuclesomes are reassembled onto the newly synthesised DNA strand [44]. The assembly and removal of the nuclesomes also occur during transcription, recombination and repair and this is all mediated by the histone chaperone protein family [44]. Hip1 is one of the members of an evolutionarily conserved family of histone chaperones that can act independently from replication [45]. Furthermore, it has been reported that the S.cerevisiae HIR complex interacts with nucleosomes and prevents the remodelling activity of the SWI/ SNF complex [46].

It has been shown that some factors are essential for DNA replication accuracy, but not DNA synthesis, as they travel with the moving replication fork. Two of those factors are Swil and Swi3 which are components of the fork stabilisation complex (FPC) [47-49]. The absence of Swi1 or Swi3 in cells leads to the accumulation of abnormal fork structures as observed with increased Rad52 DNA repair foci formation and recombination structures during the S phase [50]. The Swi1-Swi3 complex directly interacts with the DNA structure and recruits Mrc1 to the replication fork [14, 51]. The FPC also coordinates leading strand and lagging strand DNA synthesis as well as coordinating the DNA polymerase and helicase activity coupling at the replication forks $[48,49,52]$. Activation of the DNA damage response kinases in response to fork stalling agents requires the mediator protein Mrc1 [53-56] as it is present at replication forks even in the absence of DNA damage and is required for normal rates of progression of replication forks [57-60]. Swi3 is able to promote the efficient restart of stalled replication forks in a checkpointdependent manner as well as restoring broken replication forks in a checkpoint-independent manner [61]. Mrc1 is a conserved replication fork factor which is required for the stabilisation of stalled replication forks. In a manner independent of Cdc45 and Hsk1 kinase, it binds to early-firing origins [62]. Furthermore, Mrc1 also functions as a replication checkpoint mediator that allows Rad3-Rad26 to activate the effector kinase Cds1 and also interacts with Swi1-Swi3 on stabilisation of stalled replication forks [63, 64]. In the presence of fork stalling agents, Mrc1 is required to prevent continued replisome progression in the absence of DNA synthesis [65].

The aim of the study was to identify the network of genetic interactions of rad4 in S.pombe that affect its DNA replication and checkpoint functions leading to synthetically lethal phenotypes. These interactions will be explored with both rad4 and rad4-116, the temperature-sensitive rad4 mutation, using molecular techniques. Once the strains are characterised, the rad4 genetic interactions were mapped.

\section{Methods}

Yeast strains

Table 1 showing the $S$. pombe strains utilised with the corresponding genotype. The strains obtained from the Bioneer library(Bioneer Corporation, Daejeon, South Korea) are described in this paper [66].

\section{Plasmids}

Table 2 showing the plasmids utilised with the corresponding description. The plasmids were constructed to be used in the amplification of the desired gene prior to the yeast transformation process.

\section{Spore microdissection}

Cells were mated on ME agar by crossing $\mathrm{h}+$ and $\mathrm{h}-$ strains and adding sterile water. The plates were incubated at $26{ }^{\circ} \mathrm{C}$ for $3-5$ days for growth and sporulation to form zygotic asci, which were picked for tetrad dissection. After sporulation, a loop of crossed cells was streak on fresh YES or EMM plates to pick individual asci and place each spore in a grid matrix using the microdissection microscope Singer MSM System Series 400 (Singer Instruments, Somerset, UK). The four spores of the zygotic ascus were placed each at a unique position in a straight line using the micromanipulator. The plates were then incubated at $26{ }^{\circ} \mathrm{C}$. After colony formation, the plates were replicated onto YES and more importantly, selective plates of YES with an antibiotic or EMM without specific supplements using filter paper (GE Healthcare Life Sciences, Little Chalfont, UK). When the spores grow after incubation at $26{ }^{\circ} \mathrm{C}$, the plates are photographed using a ChemiDoc (Bio-Rad Laboratories Ltd., Watford, UK) for scoring and following genetic patterns. The desired genetic backgrounds for each colony was confirmed using PCR analysis. The viability of colonies on each plate was noted and total viable colonies were counted to calculate percentage viability and to 
Table 1 The fission yeast strains utilised in this study

\begin{tabular}{|c|c|c|}
\hline Strain number & Genotype & Source \\
\hline SPSC 120 & rad4-116 ura4-D18,leu1-32,ade6-M216 h+ & Collection \\
\hline SPSC 573 & rad4-GFP::kanMX cdc25-22 ura3-D18 leu1-32 ade6 h- & Collection \\
\hline SPSC 1003 & ade6-M210 leu1-32 ura4-D18 mat1_m-cyhs mt0 rpl42::cyhR(sP56Q) rad4-116::NatMX h- & Collection \\
\hline SPSC 1005 & ura4-D18, leu1-32, ade6-704 h- & Collection \\
\hline SPSC 1006 & ade6-704 ura4-D18 leu1-32 h+ & Collection \\
\hline SPSC 1017 & swi3 $\because:$ KanMX h+ ade6-M216 ura4-D18 leu1-32 h+ & {$[66]$} \\
\hline SPSC 1018 & mrc1 $1:$ :KanMX ade6-M216 ura4-D18 leu1-32 h+ & {$[66]$} \\
\hline SPSC 1026 & ade6-M216 leu1-32 ura4-D18 hip 10::KanMX h+ & Collection \\
\hline SPSC 1029 & rad4::NatMX ura4-D18 h- & Collection \\
\hline SPSC 1047 & swi3 ${ }^{\prime}:$ KanMX ura4D-18 leu1-32 ade6- $h$ - & This study \\
\hline SPSC 1048 & $\operatorname{mrc1\Delta ::KanMX}$ ura4D-18 leu1-32 ade6- $h$ - & This study \\
\hline SPSC 1049 & hip1s::KanMX ura4-D18 leu1-32 h- & This study \\
\hline SPSC 1051 & swild::KanMX h+ ade6-M216 ura4-D18 leu1-32 h+ & {$[66]$} \\
\hline SPSC 1056 & ade6-704 ura4-D18 leu1-32 rad52-GFP::KanMX6 h- & Collection \\
\hline SPSC 1063 & ade6-704 ura4-D18 leu1-32 rad52-GFP::KanMX6 mrc1::KanMX & This study \\
\hline SPSC 1064 & ade6-704 ura4-D18 leu1-32 rad52-GFP::KanMX6 swi3::KanMX & This study \\
\hline SPSC 1065 & ade6-704 ura4-D18 leu1-32 rad52-GFP::KanMX6 hip 1::KanMX & This study \\
\hline SPSC 1073 & $\begin{array}{l}\text { ade6-(704 or 210) ura4-D18 leu1-32 rad52-GFP::KanMX6 mat1_m-cyhS, smt0; } \\
\text { rpl42::cyhR (sP56Q) rad4-116::NatMX h- }\end{array}$ & This study \\
\hline SPSC 1095 & ura4-D18, leu1-32, ade6-704 leu1::hip1::SV5(x3)::ura4+ $h-$ & This study \\
\hline SPSC 1096 & ura4-D18, leu1-32, ade6-704 leu1::Swi1:::SV5(x3)::ura4+h- & This study \\
\hline SPSC 1097 & ura4-D18, leu1-32, ade6-704 leu1::Swi3::SV5(x3)::ura4+h- & This study \\
\hline SPSC 1098 & ura4-D18, leu1-32, leu1::swi1::SV5(x3)::ura4+swi1 $\Delta:$ KanMX h- & This study \\
\hline SPSC 1099 & ura4-D18, leu1-32, leu11::swi1::SV5(x3)::ura4+swi1 $:: K a n M X$ rad4-116 h+ & This study \\
\hline SPSC 1100 & ura4-D18, leu1-32, leu1::hip 1::SV5(x3)::ura4+ hip1D::KanMX h- & This study \\
\hline SPSC 1101 & ura4-D18, leu1-32, leu1::swi3::SV5(x3)::ura4+swi34::KanMX h- & This study \\
\hline SPSC 1102 & leu1::swi3::SV5(x3):::ura4+ura4-D18, ade6-704 swi34::KanMX rad4-116 h- & This study \\
\hline SPSC 1103 & leu1::hip 1::SV5(x3)::ura4+ura4-D18, ade6-704 hip10::KanMX rad4-116 h- & This study \\
\hline SPSC 1104 & leu1::swi3::SV5(x3):::ura4+ura4-D18, ade6-704 swi34::KanMX rad4-116 h+ & This study \\
\hline SPSC 1105 & leu1::hip 1::SV5(x3)::ura4+ura4-D18, ade6-704 hip1D::KanMX rad4-116 h+ & This study \\
\hline SPSC 1106 & rad52-GFP::KanMX6 leu1::Swi11::SV5(X3)::ura4+ura4-D18, ade6-704 swi1D::KanMX rad4-116::NatMX & This study \\
\hline SPSC 1108 & rad52-GFP::KanMX6 leu1::Swi3:::SV5(X3)::ura4+ura4-D18, ade6-704 swi34::KanMX rad4-116::NatMX & This study \\
\hline SPSC 1110 & rad52-GFP::KanMX6 swi14::KanMX ura4-D18 leu1-32 & This study \\
\hline SPSC 1112 & rad52-GFP::KanMX6 leu1::hip1::SV5(X3)::ura4+ ura4-D18, ade6-704 hip1D::KanMX rad4-116::NatMX & This study \\
\hline SPSC 1114 & leu1::mrc1::SV5(x3)::ura4+ura4-D18, ade6-704 h- & This study \\
\hline SPSC 1115 & leu1::mrc1::SV5(x3)::ura4+ura4-D18, ade6-704 mrcis::KanMX h- & This study \\
\hline SPSC 1116 & leu1::mrc1::SV5(x3):::ura4+ura4-D18, ade6-704 mrc14::KanMX rad4-116 & This study \\
\hline
\end{tabular}

Table 2 The plasmids used in this study.

\begin{tabular}{ll}
\hline Plasmid number & Description \\
\hline 808 & pINTL mrC1-PkC \\
809 & pINTL swi1-PkC \\
810 & pINTL swi3-PkC \\
811 & pINTL hip1-PkC \\
\hline
\end{tabular}

exam the possibility of synthetic lethality by using the chi-square test.

\section{Statistics}

The chi-square test was used to assess the possibility of synthetic lethality in experimental crosses. The viable cells or spores carried double drug-resistance markers, linked to genes, were counted as true observed value [O] 
while the expected value [E] was either calculated depending on the genetic segregation of each cross in most cases or in rare cases, as $25 \%$ of the total valid cells which include both the viable cells and the dead or unviable cells. Unviable cells are caused by either synthetic lethality or as errors in growth due to media content or micromanipulation errors, in these cases, the chi-square test eliminates the possibilities of anything but death from synthetic lethality. The general formula for the calculation of the chi-square value is as follows:

$$
X^{2}=\sum \frac{(\text { Observed Value-Expected Value }) 2}{(\text { Expected Value })}
$$

The probability associated with the value obtained from this test can be compared to a set of values from a $x^{2}$ table for $[n-1]$ degrees of freedom where $[n]$ is the number of categories. For example, in the cases where the degree of freedom value is 1 , if the $x 2$ value is greater than 3.84, it can be deduced that the difference between the observed and expected value is statistically significant $[p \leq 0.05]$ and vice versa.

\section{Lithium acetate yeast transformation}

S. pombe cells were transformed using the lithium acetate transformation method as described by Okazaki and coworkers [67].

\section{Hydroxyurea block and release}

Cells were grown in YES to mid-log phase to the same OD as measured by a spectrophotometer (typically $\sim 6 \times$ $10^{6} \mathrm{cells} / \mathrm{ml}$ ). Fresh $1 \mathrm{M}$ hydroxyurea (Sigma-Aldrich Company Ltd., Gillingham, UK) was made up in YES and then added to the growing cultures to reach $10 \mathrm{mM}$ final hydroxyurea concentration at a dilution factor of 1 : 100. At the 0 timepoint and after growth in hydroxyurea for $6 \mathrm{~h}$, the cells were precipitated by spinning down in centrifuge at $4000 \mathrm{rpm}$. Then, the supernatant was discarded and the pellet washed twice with sterile water. The cell pellets were then used for the immunofluorescence protocol.

\section{Fluorescence microscopy and immunofluorescence}

Cells were prepared for microscopy by fixing in $70 \% \mathrm{v} / \mathrm{v}$ ethanol. Welled microscope slides were used. The wells were filled with $30 \mathrm{~g} / 100 \mathrm{ml}$ agarose solution in sterile water. The agarose solution was boiled for $4 \mathrm{~min}$ then kept in a $70{ }^{\circ} \mathrm{C}$ water bath. The cells were then placed on the agarose-filled wells of the glass microscope slide. A solution of $\mu \mathrm{g} / \mathrm{ml} \mathrm{4}$,6-diamidino-2-phenylindole (DAPI) and Vectashield (Vector Laboratories Ltd., Peterborough, UK) is then added to each well. DAPI binds strongly to DNA and is excited by ultraviolet light which then emits as a blue/violet colour. The coverslip was sealed with clear nail varnish and the cells visualised. Cells were observed using the Applied Precision Deltavision microscope and the images were deconvolved using the deconvolution software. The immunofluorescence technique is described in the paper by Hagan and Hyams [68].

\section{RNA extraction and reverse transcriptase real-time PCR}

The RNA extraction and purification protocol was performed according to the manufacturer's manual of the RNA extraction kit (MCR85102) (Epicentre, Chicago, USA). The Reverse transcriptase SensiFAST SYBR NoROX kit (BIO-98005)(Bioline Reagents Limited, London, UK) reactions were performed according to the manufacturer's instructions.

\section{Protein extraction, SDS-PAGE and western blotting}

Cells were pelleted by centrifugation at $4000 \mathrm{rpm}$ for 5 min. The cells were processed immediately after centrifugation or pellets were frozen at $-80{ }^{\circ} \mathrm{C}$. The cells were then resuspended such that $100 \mu \mathrm{l}$ of Y-PER ${ }^{\mathrm{m} m}$ Yeast Protein Extraction Reagent (78990) (Thermo Fisher Scientific Inc., Altrincham, UK ) were used to resuspend 50 mg of dry cell pellet. SDS PAGE gel electrophoresis was carried out using Bio-Rad Mini Protean II kits (Bio-Rad Laboratories Ltd., Watford, UK). The western blotting technique is based on the technique described by W. N. Burnette [69].

\section{The phenotypic characterisation of the V5-tagged strains} A V5-tagged version of the tested gene under transcriptional control of the nmt81 promoter was created using plasmids p808 to p811, as shown in Table 2, and integrated at the leu1 locus following the methodology described by Fennessy and colleagues [70]. The V5-tagged base strain was constructed by transformation using SPSC 1005 as the transformed strain. The V5- tagged allele was tested using PCR and by performing a western blot of protein samples of an overnight culture of the new strain growing in EMM + uracil + leucine broth. By crossing and selecting $\mathrm{ura}^{+}$G418-resistant colonies, the strain carrying V5-tagged version of the tested gene and the deleted copy at the original gene locus was constructed. This strain was then used in a cross with SPSC 120 to introduce the rad4116 allele by selecting $\mathrm{ura}^{+}$G418 resistant temperaturesensitive colonies. The rad52-GFP-carrying strain was created by crossing. All the strains carrying the V5-tagged allele were tested using PCR before using them in the experimental procedures. The aim of this experiment was to be able to analyse the phenotypic profile of V5-tagged allele depletion for each strain in the presence of rad4-116 with control strains carrying V5-tagged allele as well as a control strain carrying $\mathrm{rad}_{4}^{+}$and a control strain carrying rad4-116. The experiment is performed at the permissive 
temperature, $26^{\circ} \mathrm{C}$, so that it can mimic the conditions of the restrictive temperature when paired with the targeted gene deletion (hip1, swil, swi3 or mrc1). All the strains were grown into cultures up to $0.8 \mathrm{OD}$ overnight at $26{ }^{\circ} \mathrm{C}$ in $\mathrm{EMM}+$ uracil+leucine (no thiamine) then inoculated into a total volume of $200 \mathrm{ml}$ EMM + uracil + leucine + 50 $\mu \mathrm{g} / \mathrm{ml}$ thiamine. The cultures were then incubated at 26 ${ }^{\circ} \mathrm{C}$ in a shaking incubator. Samples for RNA and protein extraction were collected at $0,4,8,12$ and $24 \mathrm{~h}$ till the cultures for both experimental strains reached $1.00 \mathrm{OD}$ from 0.2 OD. At each time point, samples for immunofluorescence were taken by fixing in formaldehyde. The viability of each strain was tested at each time point by plating 100 cells on $\mathrm{EMM}+$ uracil + leucine $+50 \mu \mathrm{g} / \mathrm{ml}$ thiamine agar plates in triplicates. The pellets for protein and RNA extraction were snap-frozen in liquid nitrogen and stored at - $80{ }^{\circ} \mathrm{C}$. SPSC 120 ( $\left.\mathrm{rad4}-116\right)$ and SPSC $1005\left(\mathrm{rad} 4^{+}\right)$ were used as controls, with SPSC 120 being sampled every time the experiment was repeated. The experiment was repeated four times under identical conditions and the results show the averages of the repeats. The term used for the start of the experimental procedure is thiamineinduced induction of the repression of the selected gene and shortened to "thiamine induction".
The depletion of the V5-tagged allele expression by RTQPCR

RT-QPCR was used to be able to assess the depletion of the transcript of the V5-tagged allele in the strains carrying V5-tagged allele. RNA was extracted from each strain at each time point and then purified from DNA and proteins. 50 ng of RNA of each sample was loaded per well in triplicates to able to obtain a signal for the V5 sequence. A control triplicate was loaded for the same sample to able to assess the transcription level of actin (act1). For each sample, negative control using no reverse transcriptase, negative control using no RNA sample and a negative control using no primers were loaded onto the same plate as the experimental wells. Each experiment was carried out in triplicate using separate samplings. Using the average readings for the V5 signal and the actin, the adjusted relative quantity of V5 transcript in each sample was calculated. The formula for the adjusted relative quantity value:

Adjusted relative quantity

$=($ Relative Quantity Value for Sample)

-(Relative Quantity Value for Sample without Reverse Transcriptase) $\times\left(\frac{\text { The Highest Relative Quantity Value for act1 of the same set(strain) }}{\text { Relative Quantity Value for actl of the same sample }}\right)$

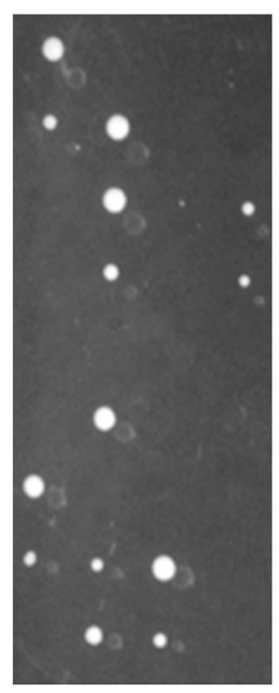

A

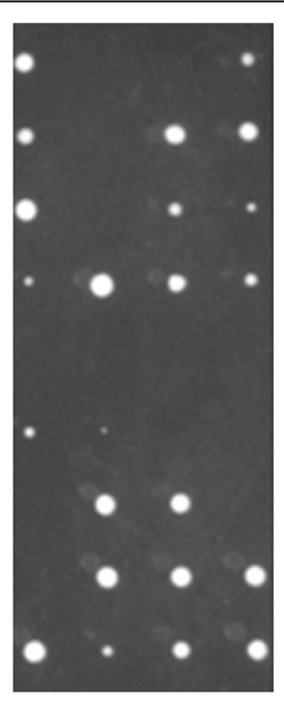

B
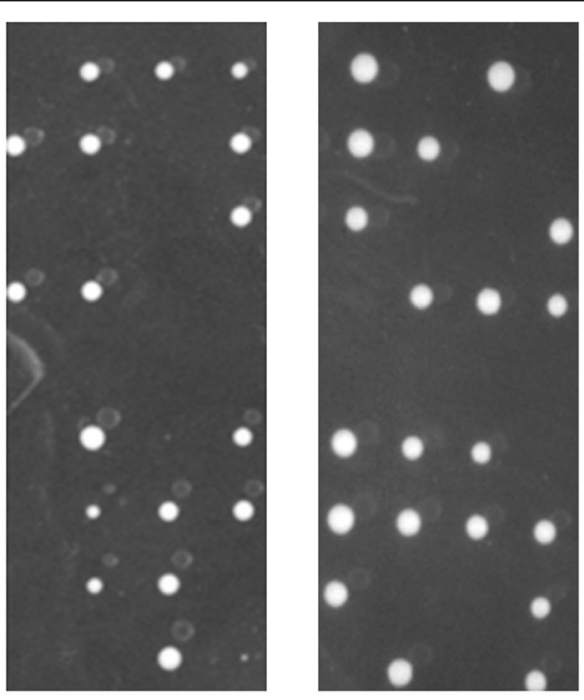

C
$\mathrm{D}$

Fig. 1 The growth of individual spores to colonies of the rad4-116 strain cross with single deletion strains. a The growth of individual spores to colonies of the rad4-116 strain cross with hip $1 \Delta$ strain. $\mathbf{b}$ The growth of individual spores to colonies of the rad4-116 strain cross with swil$\Delta$ strain. $\mathbf{c}$ The growth of individual spores to colonies of the rad4-116 strain cross with swi3 $\Delta$ strain. $\mathbf{d}$ The growth of individual spores to colonies of the rad4-116 strain cross with mrc1 $\Delta$ strain. The figure shows 4 columns of the YES plates of the crosses of the rad4-116 strain with a swil $\Delta$ strain. The cross shown was a set of spores from tetrads that were inoculated into single spores with a line separating each individual spore set from a single tetrad. The number of spores from each YES plate was counted and recorded 
Table 3 The crosses between the rad4-116 strain and single deletion strains

\begin{tabular}{lllll}
\hline Cross & hip $1 \Delta \times$ & swi1 $\Delta \times$ & swi3 $\Delta \times$ & $\operatorname{mrc1\Delta \times }$ \\
& rad4-116 & rad4-116 & rad4-116 & rad4-116 \\
\hline Wild-type & 32 & 32 & 45 & 35 \\
G418 $^{R}$ & 35 & 42 & 51 & 46 \\
NAT $^{R}$ & 30 & 32 & 46 & 41 \\
G418 $^{R} / N A T^{R}$ & 4 & 14 & 1 & 12 \\
Viability & 82 & 125 & 143 & 132 \\
Total valid spores & 144 & 192 & 212 & 180 \\
$X^{2}$ value & 27.7 & 23.4 & 22.5 & 12.8 \\
\hline
\end{tabular}

The depletion of the V5-tagged allele expression by western blotting

The protein was extracted from each strain at each time point and then purified using the Y-PER ${ }^{\mathrm{TM}}$ Yeast Protein Extraction Reagent (78990) (Thermo Fisher Scientific Inc., Altrincham, UK). Proteins separated by SDS PAGE were then transferred onto Amersham Hybond ${ }^{\mathrm{TM}}$-PVDF membranes using a transfer cell (Bio-Rad Laboratories Ltd., Watford, UK) and then probed using the primary antibodies. Each PVDF membrane was separated based on the expected signal size and each separate section was probed with its corresponding antibody. After secondary antibody probing, each PVDF membrane was wrapped in saran wrap and the chemiluminescent signal was detected and imaged using the Bio-Rad Chemidoc XRS+ Imaging System (Bio-Rad Laboratories Ltd., Watford, UK) or using an X-ray film. For each strain, the western blotting was repeated at least three times using separate samplings.

\section{Results}

\section{Synthetic lethality on agar}

The aim of the experiment was to investigate the interactions between rad4 and hip1 which is implicated in the maintenance of chromatin structure and remodelling. The strains selected had either the rad4-116 marked with NAT resistance and the hip1 1 marked with G418 resistance. This was achieved by mating the strains, after changing the mating type where needed, on EMM-nitrogen agar plates then micromanipulating and dissecting the tetrads, followed by replicating the plates on the appropriate selective media. Tetrad dissection provided clear and separated colonies on the plates, thus, facilitating the assessment of viability and avoiding contaminants forming colony-like growth. The tetrads could segregate as parental di-type, non-parental di-type or as a tetra-type depending on the combination of alleles inherited by each spore. The growth of colonies on YES indicates that the interaction between the genes present in the original spore was not synthetically lethal whereas the spores that were not able to form colonies indicate that a synthetically lethal interaction occurred in the double mutant. The original YES was replicated onto a fresh YES plate as well as YES + NAT, YES + G418 and YES + NAT + G418. The colonies were counted and the growth patterns were observed and noted for each plate and for each cross. The $x^{2}$ was then calculated based on the expected number of viable spores.

After the colonies from the crosses were noted and counted from all the plates, as seen in Fig. 1, the chisquare test was performed as shown in Table 3. As this value was calculated using the expected value based on

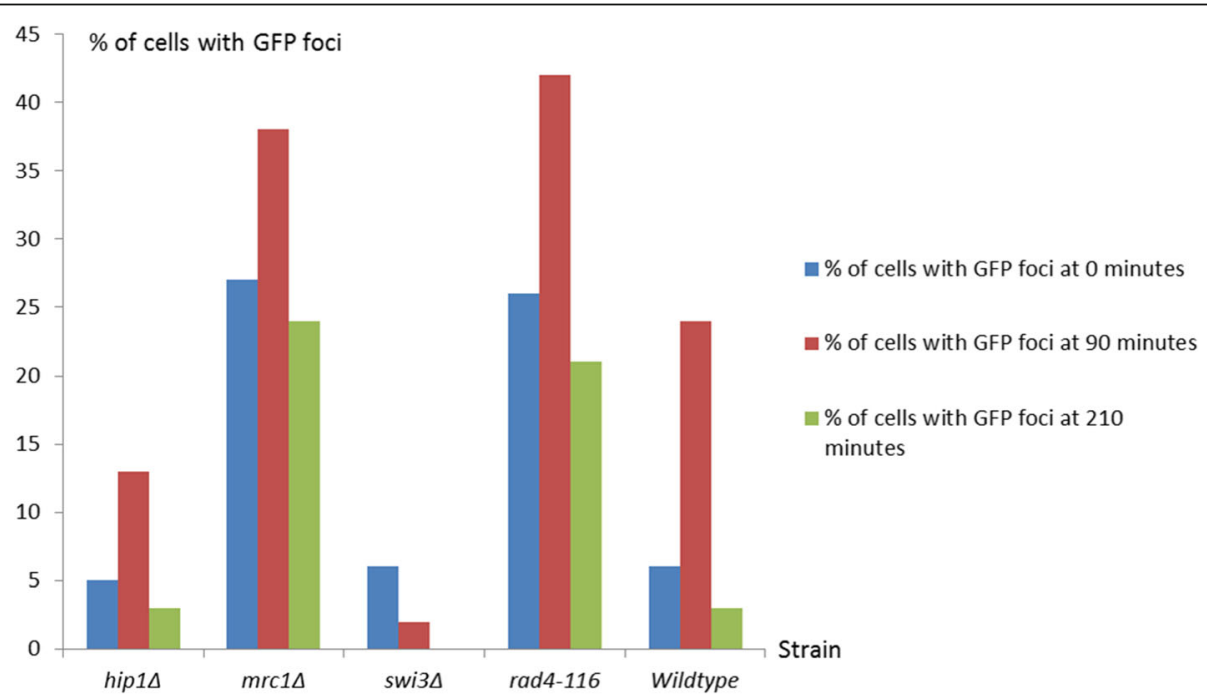

Fig. 2 A comparison of the Rad52-GFP profiles of the hip $1 \Delta, \operatorname{mrc1} \Delta$, rad4-116, rad4 ${ }^{+}$and hip $1 \Delta$ strains. The figure shows the bar chart graph representing the comparison between the percentage of cells with Rad52-GFP foci across the strains at the start of the experiment, at 90 min after the start and at the end of the experiment at $210 \mathrm{~min}$ 


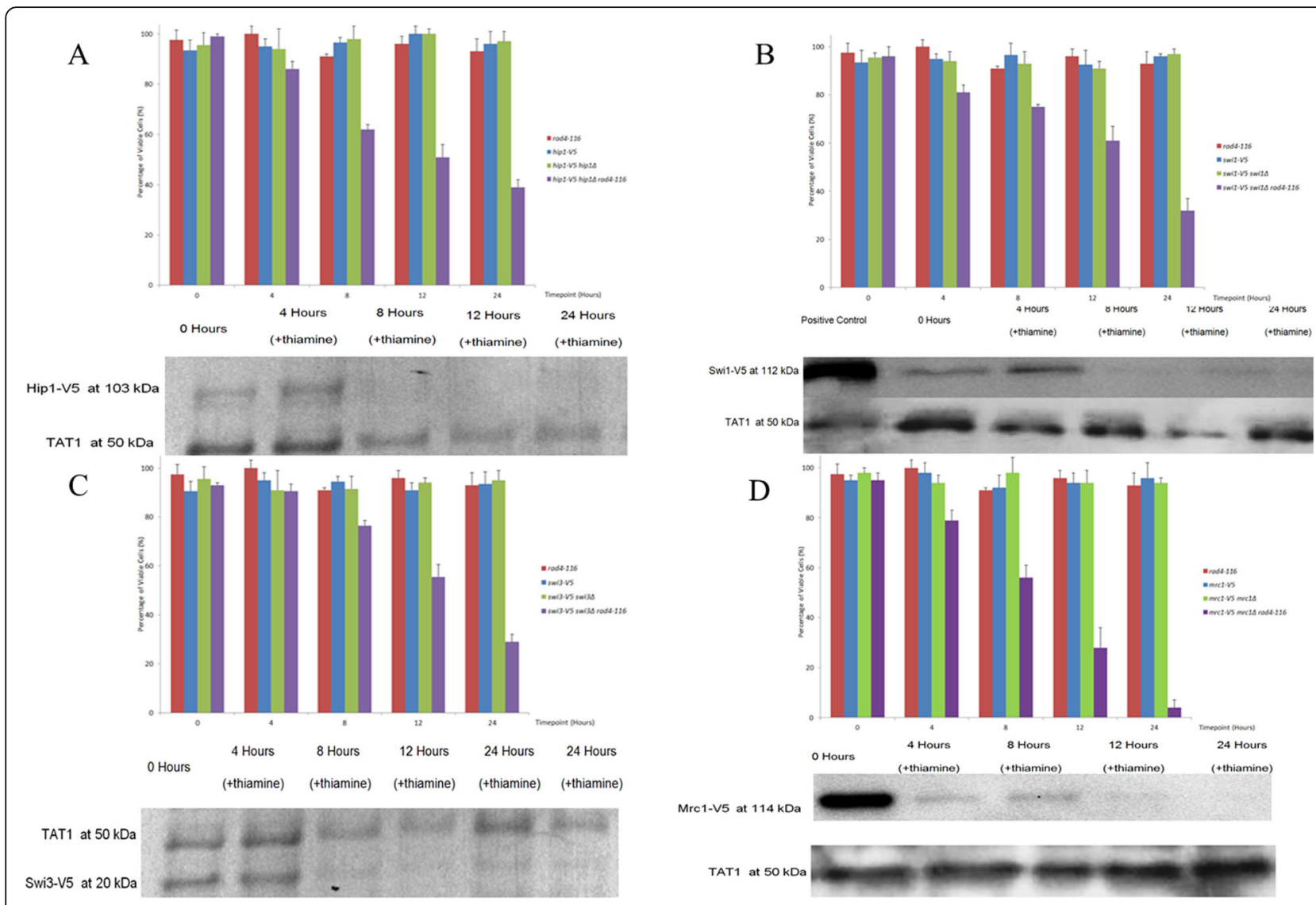

Fig. 3 The graphical representation of the viability comparison of strains carrying the V5 alleles against the control rad4-116 strain across the 24-h timecourse after the addition of thiamine to the media. For the strains carrying both the $V 5$ alleles, deletions of the wildtype genes and the rad4116 gene, the western blots of the depletion of V5 tag are shown. a Among all the hip 1-V5 strains, only SPSC 1103 showed a gradual loss of viability dropping from $99 \%$ viability at 0 time point to $51 \%$ after $12 \mathrm{~h}$, then to $39 \%$ viability at $24 \mathrm{~h}$. All the other strains represented showed no significant loss of viability across the 24-h timecourse ranging from 100 to $91 \%$ viability. The western blot of SPSC 1103 shown represents the samples after being probed with anti-V5 (top signal) and anti-TAT1 (bottom signal) as control. The 0- and 4-h samples expressed the V5 tag while there was no visible signal for the 8-, 12- or 24-h samples. The TAT1 signal showed no signs of depletion across all 5 samples. $\mathbf{b}$ Among all the swi1-V5 strains, only SPSC 1099 showed a gradual loss of viability dropping from $96 \%$ viability at 0 time point to $61 \%$ after $12 \mathrm{~h}$, then to $32 \%$ viability at $24 \mathrm{~h}$. All the other strains represented showed no significant loss of viability across the 24-h timecourse ranging from 100 to $91 \%$ viability. The western blot of SPSC 1099 shown represents the samples after being probed with anti-V5 (top signal) and anti-TAT1 (bottom signal) as control. The 0, 4 and 8-h samples expressed the V5 tag while there was no visible signal for the 12- or 24-h samples. An additional positive control SPSC 1099 sample is shown on the right where no thiamine is added. c Among all the swi3-V5 strains, only SPSC 1102 showed a gradual loss of viability dropping from $93 \%$ viability at 0 time point to $56 \%$ after $12 \mathrm{~h}$, then to $29 \%$ viability at $24 \mathrm{~h}$. All the other strains represented showed no significant loss of viability across the 24-h timecourse ranging from 100 to $91 \%$ viability. The western blot of SPSC 1102 shown represents the samples after being probed with anti-TAT1 (top signal) and anti-V5 (bottom signal) as control. The 0- and 4-h samples expressed the V5 tag while there was no visible signal for the 8-, 12- or 24-h samples. An additional sample at $24 \mathrm{~h}$ was taken to underline the complete depletion of the V5 tag. d Among all the mrc1-V5 strains, only SPSC 1116 showed a gradual loss of viability dropping from $95 \%$ viability at 0 time point to $28 \%$ after $12 \mathrm{~h}$, then to $4 \%$ viability at $24 \mathrm{~h}$. All the other strains represented showed no significant loss of viability across the $24-\mathrm{h}$ timecourse ranging from 100 to $91 \%$ viability. The western blot of SPSC 1116 shown represents the samples after being probed with anti-V5 (top signal) and anti-TAT1 (bottom signal) as control. The 0-h sample strongly expressed the V5 tag while the 4- and 8-h samples expressed very weak V5 signals, but there were no visible signals for the 12- or 24-h samples

the segregated spores not based on the expected segregation pattern, the values represent a focused measure on whether the double mutants were synthetically lethal or not. These values were all greater than 3.84 , which was the threshold value at $p \leq 0.05$ with a degree of freedom of 1. This indicated that the deletion of hip1, swi1, swi3 and $m r c 1$, separately were synthetically lethal when combined with rad4-116 separately, and that any lethality or observed lack of growth would not be due to chance or random occurrence.

Table 3 shows the crosses between the rad4-116 strain and single deletion strains. The rad4-116 was tagged with NAT resistance while the $m r c 1$ deletion was marked with G418 (Kanamycin) resistance. The crosses 


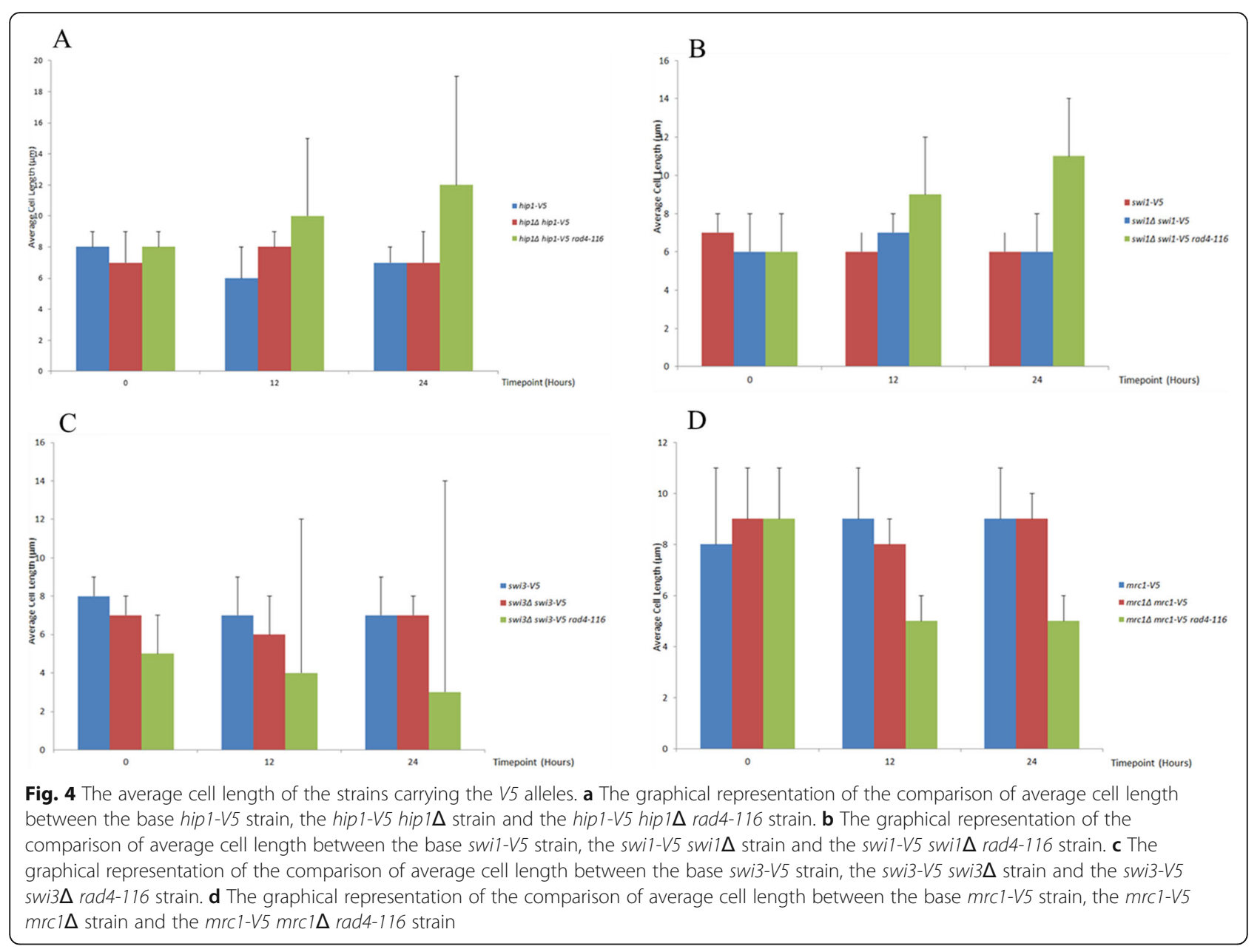

were carried out on EMM-nitrogen agar, then checked after 2 days for sporulation. The tetrads from sporulation were separated using the Singer Micromanipulator onto YES agar plates. After 4 days, the plates were then copied onto fresh YES, as shown in Fig. 1, YES+G418 and YES+NAT plates separately. After another 3 days, the colonies on each plate were counted and recorded as seen in the table. Viability was measured by counting the observed colonies on the YES agar plates. Therefore, those colonies were able to be copied and re-grown for analysis. The $\chi^{2}$ value for each cross was calculated and tabulated at $p \leq 0.05$ with a degree of freedom of 1 .

\section{Hydroxyurea block and release}

Cells were grown in liquid media then arrested by the addition of hydroxyurea which blocks ribonucleotide reductase leading to the depletion of the ribonucleotides, halting DNA replication. Strains carrying separate mutations of rad4-116 or deletions of hip1, swil, swi3 and $m r c 1$ were crossed with strains expressing Rad52-GFP to create the experimental strains for this procedure. The use of Rad52-GFP fluorescent foci represented an effective method to assess the accumulation of stalled or collapsed fork events during replication as shown in previous studies [50]. Then, after $6 \mathrm{~h}$ of arrest with hydroxyurea, the cells were released by the depletion of hydroxyurea from the media, washing the cells, then resuspending in rich YES media. Samples were collected every $30 \mathrm{~min}$ for $210 \mathrm{~min}$ to be analysed for fluorescence microscopy and testing viability. The timepoint 0 represents the first time point after resuspension of the culture in YES media. All of the procedures including culturing, washing, resuspension and sampling were carried out at $26^{\circ} \mathrm{C}$.

The cell nuclei were assessed by observing and calculating the number and of nuclei that carry GFP fluorescent foci spanning the $210 \mathrm{~min}$ compared to the starting time point $(0)$ of the release. The number of nuclei carrying GFP foci was divided over the total number of nuclei to provide the percentage observed in the graphical representation in Fig. 2. It is important to note that none of the strains with Rad52-GFP showed a decrease in viability across the 210-min timecourse. 


\section{The phenotypic characterisation of the V5-tagged strains}

\section{The viability of the V5-tagged strains across $24 \mathrm{~h}$}

With regard to the depletion phenotypes of strains with rad4-116 backgrounds, the viability profiles for Swi1 and Swi3 were most similar as observed in Fig. 3. All the strains carrying the gene deletion, the V5-tagged allele of the same gene and the rad4-116 gene showed a gradual decrease in viability from time point 0 to time point

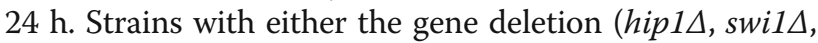
swi3 $\Delta, m r c 1 \Delta$ ) and/or the V5-tagged allele (hip1-V5, swi1-V5, swi3-V5, mrc1-V5) and rad4 ${ }^{+}$showed no decrease in viability from timepoint 0 across the 24 h timecourse after thiamine addition as observed in Fig. 3. Figure 3 also contained a rad4-116 control with no gene mutations or V5-tagged alleles that did not show any decrease in viability and was repeated every time a strain was sampled. The strain that showed the highest level of viability loss was the mrc1 $1 \Delta$ mrc1- $V 5$ rad4-116 dropping from $95 \%$ at time point 0 to $4 \%$ after $24 \mathrm{~h}$ for a total loss of $91 \%$ as observed in Fig. 3. In one repetition of $m r c 1 \Delta$ mrc1-V5 rad4-116 sampling, the three EMM agar plates showed no colonies growing with the expectancy of 100 viable colonies of each in case of $100 \%$ viability. In terms of V5 RNA and protein expression, all the strains with V5-tagged genes (hip1-V5, swi1-V5, swi3-V5, mrc1-V5) showed a gradual decrease across the $24 \mathrm{~h}$ after thiamine addition. Generally, using western blotting, the V5 signal is abolished at the 8- or 12-h timepoint with a strong signal observed at the initial time point 0 and a weaker signal observed at time point $4 \mathrm{~h}$ with no change observed in the $\alpha$-Tubulin control protein expression. The decrease and eventual abolishment of the detectable V5tagged protein signal is consistent with the decrease in V5 transcription of each gene. In addition, in the strains carrying the gene deletion, the V5-tagged allele of the

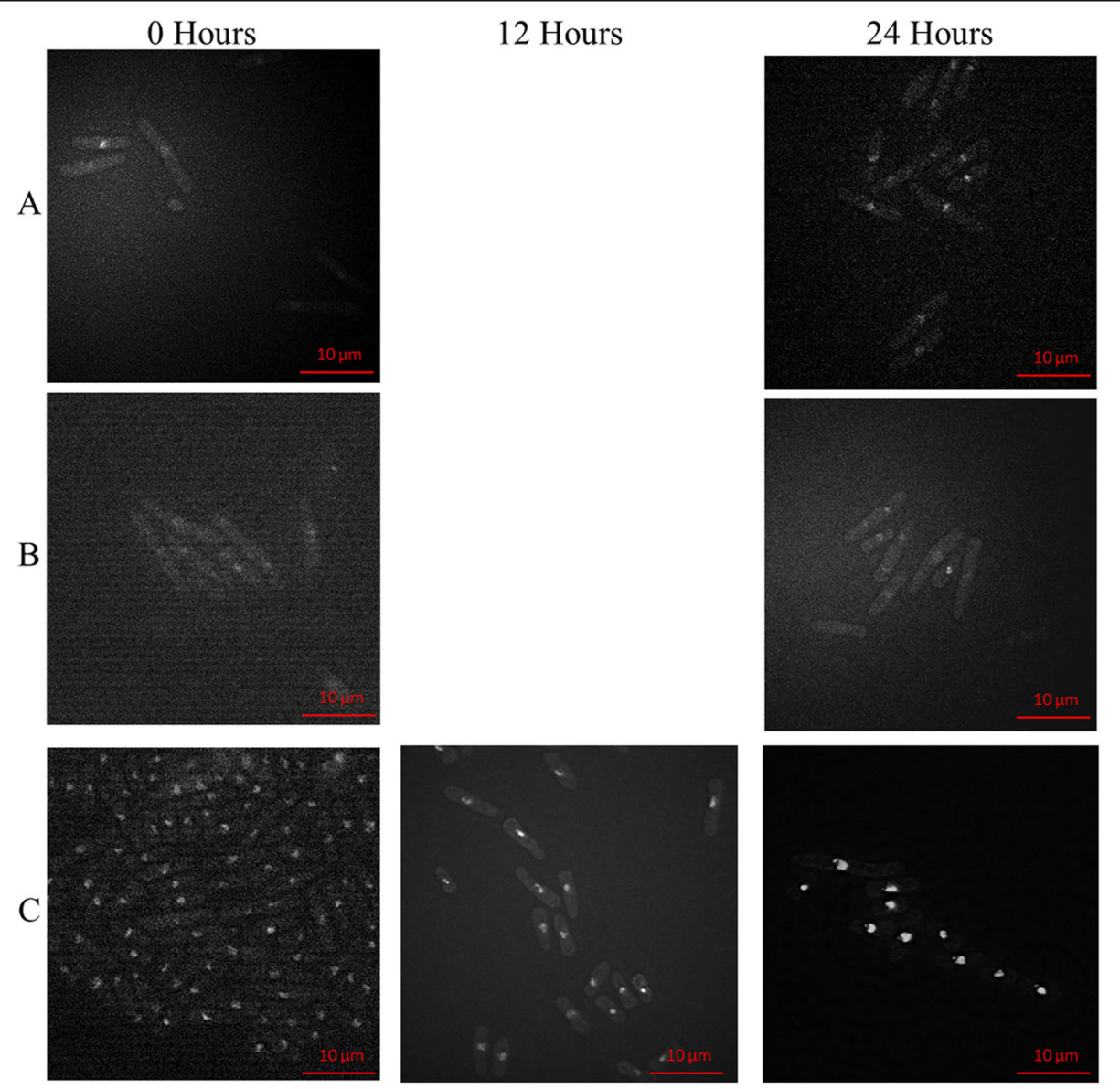

Fig. 5 The cell morphology of the strains carrying the hip 1-V5 allele across $24 \mathrm{~h}$ after thiamine induction. The figure shows the cells of the a hip 1-

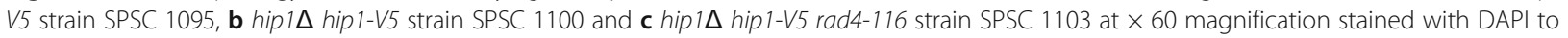
show the nuclei at the $0 \mathrm{~h}$ time point and the $24 \mathrm{~h}$ timepoint. An additional time point at $12 \mathrm{~h}$ is shown for the SPSC 1103 strain. For SPSC 1095 and SPSC 1100, there was no significant difference between the cells across those 2 time points in terms of cell length, cell shape and nuclear shape. For SPSC 1103, the cells showed two distinct phenotypes that develop from timepoint 0 to 12 to $24 \mathrm{~h}$, for cells to increase or decrease in length. The nuclei of most of these cells showed a fragmentation that becomes more pronounced at the $24 \mathrm{~h}$ time point and some cells showed a compacted nucleus. The phenotypical effect of thiamine addition on the hip 1-V5 strains across $24 \mathrm{~h}$ 
same gene and the rad4-116 gene, the depletion of V5 RNA (as seen in Supplementary Data Figure S1) and protein signals were consistent with the development of cellular phenotypes in terms of cell length, nuclear integrity and size, typically present at $12 \mathrm{~h}$ and more pronounced at $24 \mathrm{~h}$.

In the experiment with hip1 $\Delta$ hip1-V5 rad4-116 strain SPSC 1103, two distinct phenotypes were observed at time points 12 and $24 \mathrm{~h}$. The more common phenotype being longer of more than $10 \mu \mathrm{m}$ in length and the less common phenotype being a shorter cell of less than 7 $\mu \mathrm{m}$ in length as observed in Fig. 5. Both phenotypes show irregular nuclear size and shape with some nuclei being elongated and others fragmented or compacted.

In the swi1d swi1-V5 rad4-116 strain SPSC 1099, a single phenotype was observed at time points 12 and $24 \mathrm{~h}$ as seen in Fig. 6. A significant increase occurs from $6 \mu \mathrm{m}$ to $9 \mu \mathrm{m}$ at $12 \mathrm{~h}$ before reaching $11 \mu \mathrm{m}$ at $24 \mathrm{~h}$ after the addition of thiamine as shown graphically in Fig. 4. The cells also show multiple cellular polarisation with a common phenotype being 3 cytoplasmic ends. The increase in cell length was accompanied by a fragmentation of nuclei and the emergence of compact nuclei and occasionally cells showing no DAPI staining indicating uneven nuclear division.

With regard to the swi3-V5 swi34 rad4-116 strain SPSC1102, two distinct phenotypes were observed at timepoints 12 and $24 \mathrm{~h}$ as seen in Fig. 7. The more common phenotype being shorter of less than $5 \mu \mathrm{m}$ in length and the less common phenotype being a longer cell of more than $5 \mu \mathrm{m}$ in length as observed in Fig. 7. Both phenotypes show irregular nuclear size and shape with some nuclei being elongated or compacted.

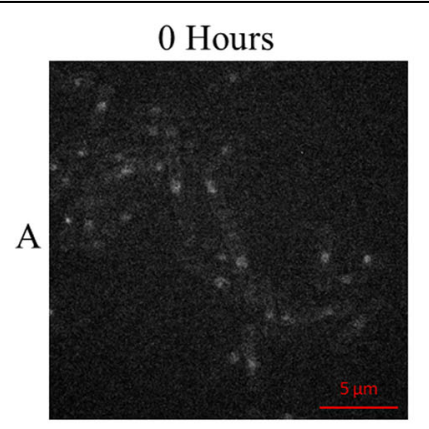

12 Hours

24 Hours
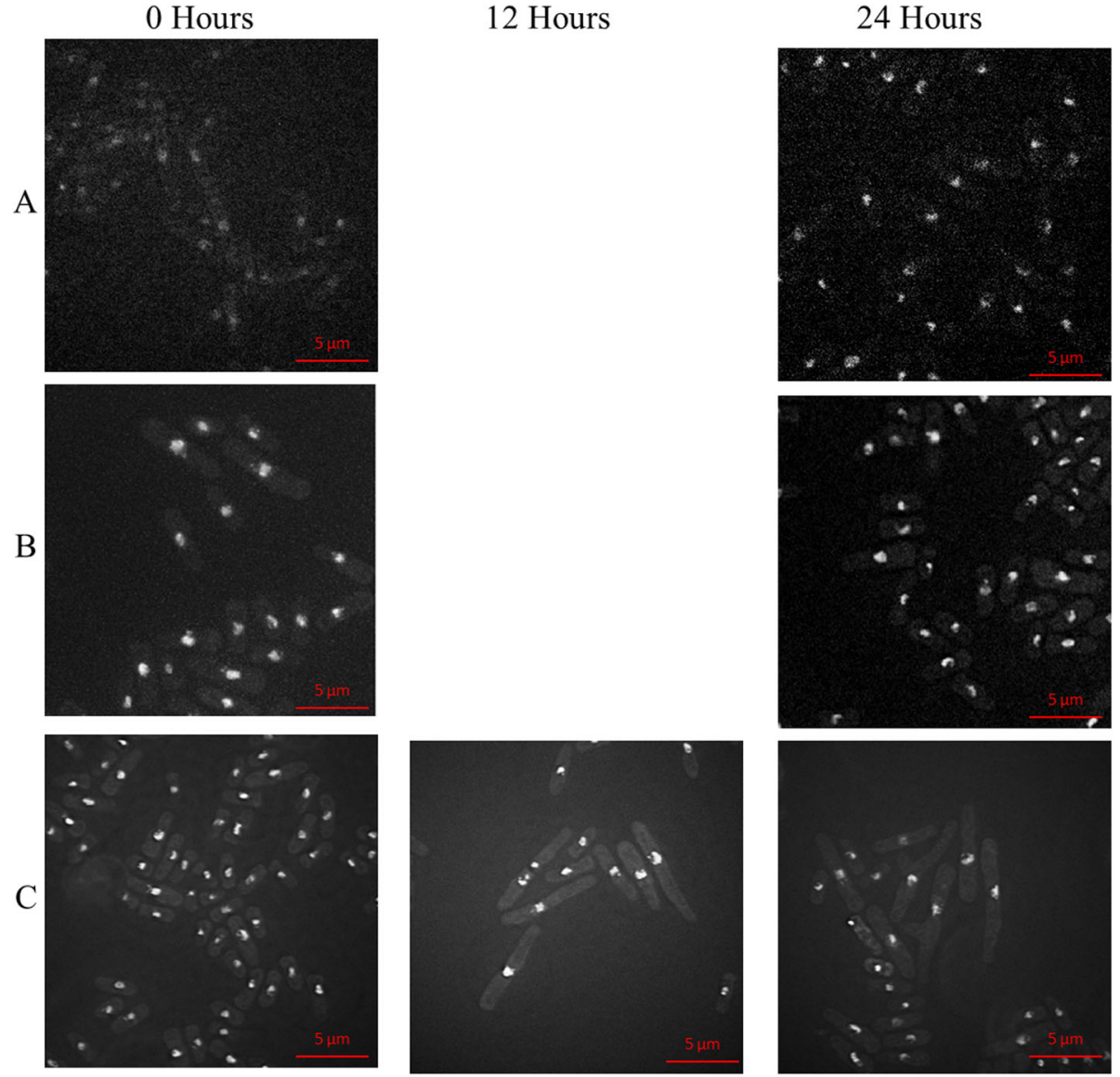

Fig. 6 The cell morphology of the strains carrying the swi1-V5 allele across $24 \mathrm{~h}$ after thiamine induction. The figure shows the cells of the (a) swi1-V5 strain SPSC 1096, (b) swi1 s swi1-V5 strain SPSC 1098 and c swi14 swi1-V5 rad4-116 strain SPSC 1099 at $\times 100$ magnification stained with DAPI to show the nuclei at the $0 \mathrm{~h}$ time point and the $24 \mathrm{~h}$ timepoint. An additional time point at $12 \mathrm{~h}$ is shown for the SPSC 1099 strain. For SPSC 1096 and SPSC 1098, there was no significant difference between the cells across those 2 time points in terms of cell length, cell shape and nuclear shape. For SPSC 1099, the cells showed a distinct phenotype, that developed from timepoint 0 to 12 to $24 \mathrm{~h}$, for cells to increase in length. The nuclei of most of these cells showed a fragmentation that became more pronounced at the 24-h timepoint and some cells showed a compacted nucleus. Some mutant cells showed an abnormal cell shape with one nucleus and three ends to the cytoplasm. The phenotypical effect of thiamine addition on the swi1-V5 strains across $24 \mathrm{~h}$ 
As for the mrc1-V5 mrc1 $\mathrm{rad4-116}$ strain SPSC 1116, the cells show a distinct phenotype, that develops at timepoints 12 and $24 \mathrm{~h}$ as seen in Fig. 8. The initial average cell length at 0 is similar to the other two mrc1-V5 strains, but then a significant decrease occurs from $9 \mu \mathrm{m}$ to $5 \mu \mathrm{m}$ at both 12 and $24 \mathrm{~h}$ after the addition of thiamine as observed in Fig. 4. The decrease in cell length was accompanied by fragmentation and compaction of nuclei with the shape of the nuclei.

The effect of thiamine addition on the average cell length of the V5-tagged strains across $24 \mathrm{~h}$

No significant change in average cell length occurred in both the base hip1-V5 strain and the hip1-V5 hip1A strain as the value is between 6 and $8 \mu \mathrm{m}$ between 0 and $24 \mathrm{~h}$ to finally reach $7 \mu \mathrm{m}$ for both strains at $24 \mathrm{~h}$ after thiamine addition. As for the hip1-V5 hip14 rad4-116 strain, the initial average cell length at 0 was similar to the other two strains at $8 \mu \mathrm{m}$. However, a gradual increase was then observed from $8 \mu \mathrm{m}$ to $10 \mu \mathrm{m}$ at $12 \mathrm{~h}$ then $12 \mu \mathrm{m}$ at $24 \mathrm{~h}$ after the addition of thiamine. The cells of the hip1-V5 hip1s rad4-116 strain contained two phenotypic cell sizes with the predominant one being an elongated cell of more than $13 \mu \mathrm{m}$ in length and the other, less common, much shorter phenotype, being of 3 to $5 \mu \mathrm{m}$ in length. The presence of high-value error bars indicated the presence of different phenotypes for the same strain.

No significant change in average cell length occurred in both the base swi1-V5 strain and the swi1-V5 swild strain as the value is between 7 and $6 \mu \mathrm{m}$ between the 0 and $24 \mathrm{~h}$, eventually reaching $6 \mu \mathrm{m}$ at $24 \mathrm{~h}$ after thiamine addition. As for the swi1-V5 swi1s rad4-116 strain, the initial average cell length at 0 was similar to the other two strains at $6 \mu \mathrm{m}$, but then a significant

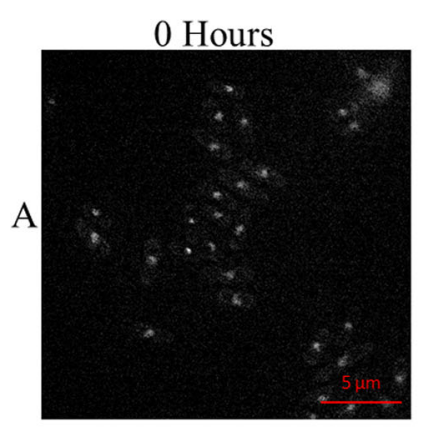

12 Hours
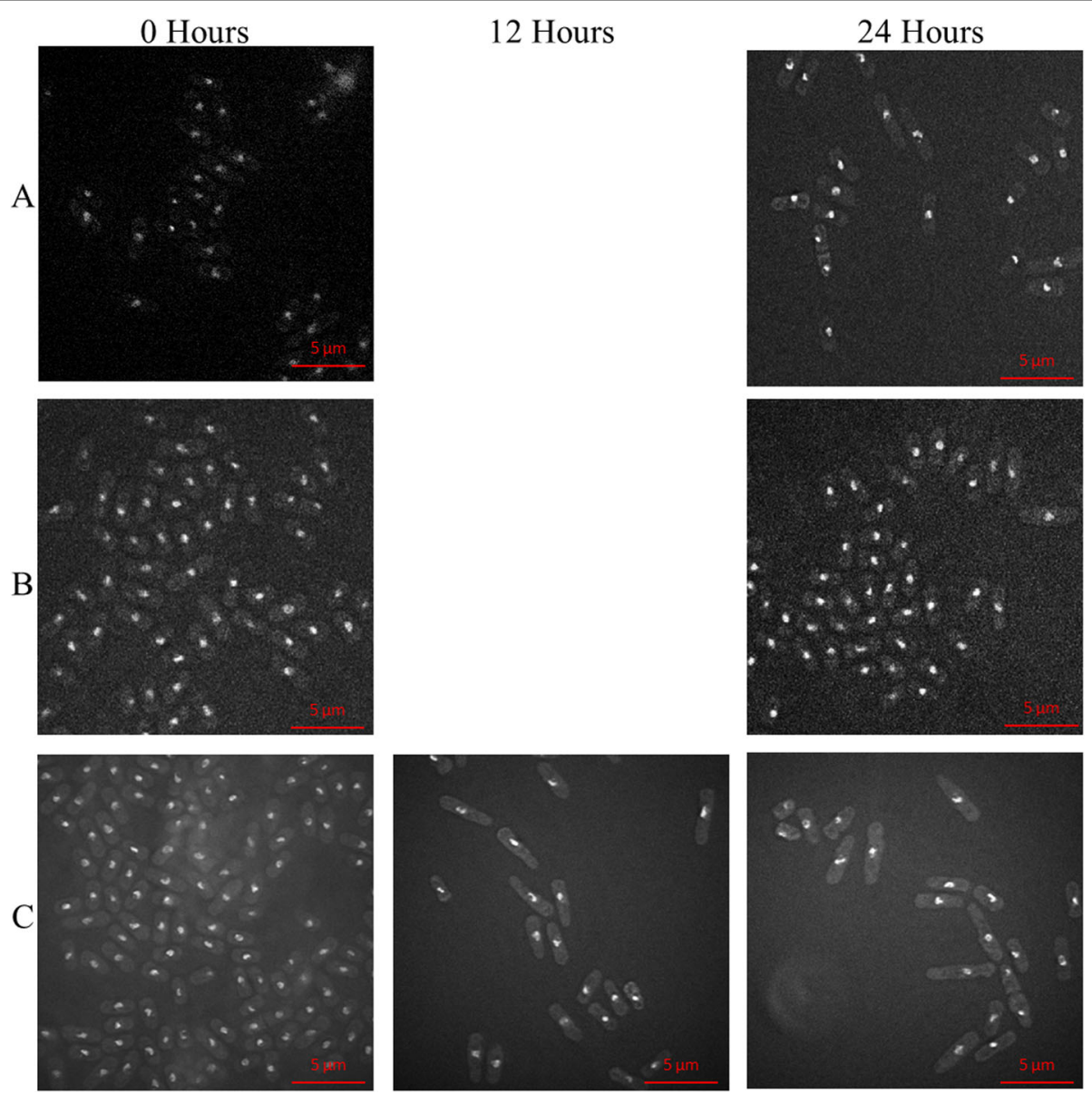

Fig. 7 The cell morphology of the strains carrying the swi3-V5 allele across $24 \mathrm{~h}$ after thiamine induction. The figure shows the cells of the (a) swi3-V5 strain SPSC 1097 (b) swi3 s swi3-V5 strain SPSC 1101 and (c) swi3 s swi3-V5 rad4-116 strain SPSC 1102 at $\times 100$ magnification stained with DAPI to show the nuclei at the $0 \mathrm{~h}$ time point and the $24 \mathrm{~h}$ timepoint. An additional time point at $12 \mathrm{~h}$ is shown for the SPSC $1102 \mathrm{strain}$. For SPSC 1097 and SPSC 1101, there was no significant difference between the cells across those 2 time points in terms of cell length, cell shape and nuclear shape. For SPSC 1102, the cells showed two distinct phenotypes, that developed from timepoint 0 to 12 to $24 \mathrm{~h}$, for cells to increase or decrease in length. The nuclei of most of these cells showed irregular nuclear shapes that became more pronounced at the 24-h time point and some cells showed a compacted nucleus. The phenotypical effect of thiamine addition on the swi3-V5 strains across $24 \mathrm{~h}$ 


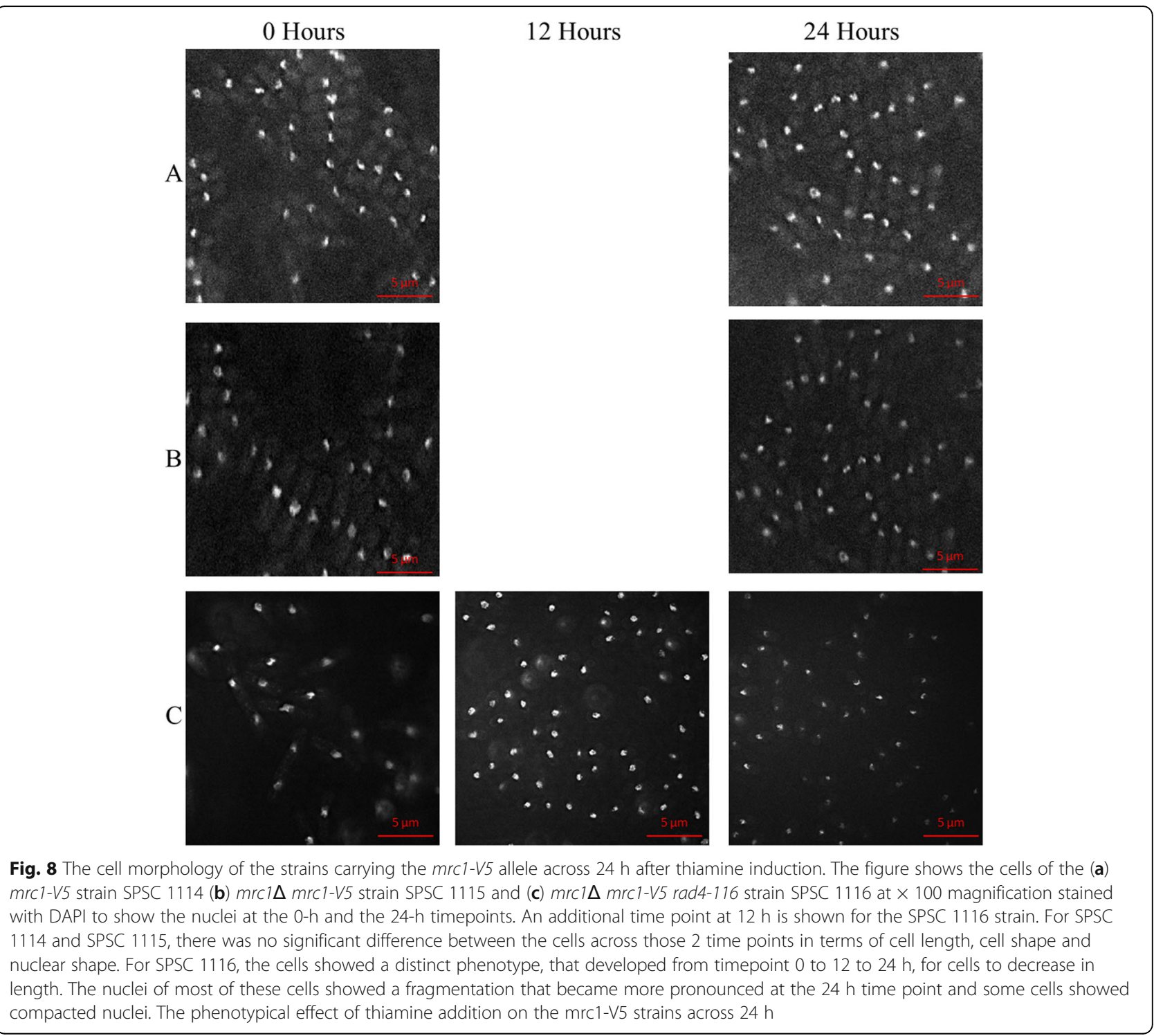

increase occurred from $6 \mu \mathrm{m}$ to $9 \mu \mathrm{m}$ at $12 \mathrm{~h}$ before reaching $11 \mu \mathrm{m}$ at $24 \mathrm{~h}$ after the addition of thiamine.

No significant change in average cell length occurred in both the base swi3-V5 strain and the swi3-V5 swi3A strain as the value is between 6 and $8 \mu \mathrm{m}$ between the 0 $\mathrm{h}$ and $24 \mathrm{~h}$ to finally reach $7 \mu \mathrm{m}$ for both strains at $24 \mathrm{~h}$ after thiamine addition. As for the swi3-V5 swi3A rad4116 strain, the initial average cell length at 0 was lower than the other two strains at $5 \mu \mathrm{m}$. A gradual decrease was then observed from $5 \mu \mathrm{m}$ to $4 \mu \mathrm{m}$ at $12 \mathrm{~h}$ then 3 $\mu \mathrm{m}$ at $24 \mathrm{~h}$ after the addition of thiamine. The cells of the swi3-V5 swi34 rad4-116 strain contained two phenotypic cell sizes with the predominant one being a short, almost spherical, cell of 2 to $3 \mu \mathrm{m}$ in length and the other, less common phenotype, being of 9 to $12 \mu \mathrm{m}$ in length. The presence of high-value error bars indicated the presence of different phenotypes for the same strain.

No significant change in average cell length occurred in both the base mrc1-V5 strain and the mrc1-V5 mrc1 $\Delta$ strain as the value is between 8 and $9 \mu \mathrm{m}$ between the 0 $\mathrm{h}$ and $24 \mathrm{~h}$ after thiamine addition. As for the $m r c 1-V 5$ $m r c 1 \Delta$ rad4-116 strain, the initial average cell length at 0 was similar to the other two strains, but then a significant decrease occurred from $9 \mu \mathrm{m}$ to $5 \mu \mathrm{m}$ at both $12 \mathrm{~h}$ and $24 \mathrm{~h}$ after the addition of thiamine.

\section{Discussion}

The synthetic lethality data obtained by crossing rad4-116 and hip1 1 , swi1 1 , swi3 $\Delta$ and $m r c 1 \Delta$ separately provided confirmation of the preliminary SGAA screen. As observed in Table 1, all the crosses produced statistically 
significant synthetically lethal phenotypes. This further proves the synthetical interaction between rad4-116 on one side and hip $1 \Delta$, swi1s, swi3 $\Delta$ and $m r c 1 \Delta$ separately on the other side. The synthetic lethality profiles of swil $\Delta$ and swi3 $\Delta$ are nearly identical to each other in terms of the $X^{2}$ values being 23.4 and 22.5 . The synthetic lethality profile of hip $1 \Delta$ was also similar to swi1s and swi3 $\Delta$ profiles with a $\chi^{2}$ value of 27.7. However, surprisingly, the synthetic lethality profile of $m r c 1 \Delta$ was not as similar to hip1 $1 \Delta$, swi1 $\Delta$ and swi3 $\Delta$ profiles in terms of $\chi^{2}$ value as the $\chi^{2}$ value was 12.8. Indeed, all the $\chi^{2}$ values were statistically significant showing lethality. The difference of synthetic lethality profiles is interesting given that Swi1, Swi3 and Mrc1 act to stabilise stalled replication forks $[14,51]$. However, it should be noted that the Swi1-Swi3 complex recruits Mrc1 onto the replication fork [14].

In terms of the DNA replication stalled fork profiles, a similar pattern was observed. The hip1A, swi1s and swi3 $\Delta$ DNA replication stalled fork recovery profiles are similar in terms of peak value of nuclei and recovery with Rad52-GFP foci as observed in Fig. 2. The DNA replication stalled fork recovery profiles of swi $1 \Delta$ and swi3 $\Delta$ were less similar than their synthetic lethality profiles with the swi3 $\Delta$ strain showing a very low accumulation of Rad52-GFP foci even when compared to the $\mathrm{rad}_{4}^{+}$strain as observed in Fig. 2. Furthermore, a strong similarity was observed between the rad4-116 and $m r c 1 \Delta$ DNA replication stalled fork profiles as observed in Fig. 2. The full profiles across the full 210-min timecourse showed the same pattern in terms of starting level of percentage of cells with Rad52-GFP foci, the increase up to a similar peak level, maintenance of a steady level of foci and final level observed at $210 \mathrm{~min}$ as illustrated in Fig. 2. These findings for $m r c 1 \Delta$ are consistent with those presented previously in S.cerevisiae [65]. The rad4-116 and $m r c 1 \Delta$ strains are the only two strains that do not recover below the starting level of RAd52-GFP foci as observed in Fig. 2. The accumulation of Rad52-GFP in swild and swi3 $\Delta$ strains were similar, albeit no reaching the same level of accumulation, as those noted in previous studies [50,61, 71].

In the experiment with hip1s hip1-V5 rad4-116 strain SPSC 1103, two distinct phenotypes were observed at timepoints 12 and $24 \mathrm{~h}$. The more common phenotype being longer of more than $10 \mu \mathrm{m}$ in length and the less common phenotype being a shorter cell of less than $7 \mu \mathrm{m}$ in length as observed in Fig. 5 . Both phenotypes show irregular nuclear size and shape with some nuclei being elongated and others fragmented or compacted. The fragmented nuclei, as observed in Figs. 4 and 5, were to be expected as the HIRA proteins, including Hip1, have been proven to be integral in histone modification and chromatin structure $[46,72]$.
In the swi1d swi1-V5 rad4-116 strain SPSC 1099, the increase in cell length was accompanied by a fragmentation of nuclei and the emergence of compact nuclei and occasionally cells showing no DAPI staining indicating uneven nuclear division. This is consistent with the role of Swil (Tof1) in terms of function in paused fork resolution and for stable association of replisome components with sites of DNA synthesis in the presence of hydroxyurea $[65,73,74,75]$. This may also indicate additional roles of Swil in terms of chromatin structure maintenance that may be affected by Rad4.

With regards to the swi3-V5 swi3A rad4-116 strain SPSC1102, it should be noted that nuclear fragmentation was not observed unlike those observed in the swi1s swi1-V5 rad4-116 and hip1D hip1-V5 rad4-116 strains. The appearance of the shorter length phenotype not seen in the swild swi1-V5 rad4-116 strain was interesting, indicating a function exclusive to Swi3 not present in Swil. The difference in phenotypes between swi1 swi1-V5 rad4-116 and swi3-V5 swi3山 rad4-116 was also interesting given that Swil and Swi3 act to stabilise stalled replication forks as the same complex $[14,51]$.

As for the mrc1-V5 mrc1A rad4-116 strain SPSC 1116, the decrease in cell length was accompanied by fragmentation and compaction of nuclei with the shape of the nuclei similar to those seen in swi14 swi1-V5 rad4-116 and hip1D hip1-V5 rad4-116 strains. The phenotype in the $m r c 1-V 5$ mrc1 $\Delta$ rad4-116 strain was similar to the shorter phenotype of the swi3-V5 swi3A rad4-116 strain in terms of cell length. This is consistent with the role of Mrc1 as a conserved replication fork factor and its interaction with Swi1-Swi3 complex [62, 64]. It is important to note the similarity in phenotype between the shorter phenotype of the swi3-V5 swi3A rad4-116 strain and $m r c 1-V 5 m r c 1 \Delta$ rad4-116 strain on the one hand and the similarity between longer phenotype of the swi3-V5 swi34 rad4-116 and hip14 hip1-V5 rad4-116 strain in terms of cell length. It should be noted that the rad4116 interaction with the gene deletions (hip1A, swi1s, swi3 $\Delta, m r c 1 \Delta$ ) was most likely due to the development of stalled replication forks, with eventual fork collapse, and double strand breaks as the rad4-116 allele mimics conditions of replication stress in the absence of checkpoint function [43]. However, that does not rule out additional interactions based on the other roles of Rad4 which led to the development of different and distinct phenotypes as the V5-tagged genes were deleted in the presence of rad4-116 leading to eventual cell death.

\section{Conclusion}

This study identified that the non-essential genes, $m r c 1$, swi1, swi3 and hip1, are required for survival under replication stress. The role these genes play in the resolution of DNA replication forks in combination with the 
loss of function from the hypomorphic rad4-116, appears to be the driving cause of the synthetic lethality of the double mutant strains. The inability of cells to recover from the fork stalling, and subsequent collapse caused cells to die during the depletion of the tested gene. In summary, this study provides the phenotypic analysis of strains to be able to identify non-essential genes required for survival under conditions of DNA stress. The work carried out in S. pombe could be built upon in higher eukaryotes to be able to map the interactions of TopBP1.

\section{Supplementary information}

Supplementary information accompanies this paper at https://doi.org/10. 1186/s43141-020-00025-X.

Additional file 1: Supplemental Figure S1 showing the comparison the adjusted relative quantity of RNA of strains carrying the V5 alleles. The figure shows the gradual decrease through graphical representation of the adjusted relative quantity between all the (A) Hip1-V5, (B) Swi1-V5, (C) Swi3-V5 and (D) Mrc1-V5 strains across the 24 hour timecourse after the addition of thiamine to the media.

\begin{abstract}
Abbreviations
ATR: ATM and Rad3 related; BRCA: Breast cancer; BRCT: BRCA1 C-terminal domain; Cdc: Cell division cycle; CDK: Cyclin-dependent kinase;

CHK1: Checkpoint 1; DAPI: 4',6-diamino-2-phenyl-indole; DDK: Dbf4pdependent kinase; DNA: Deoxyribonucleic acid; EMM: Edinburgh minimal medium; FACS: Fluorescent-activated cell sorting; G: Guanine; G1: Gap/ growth phase 1; G2: Gap/growth phase 2; G2/M: The growth phase 2/mitosis boundary of the cell cycle; G418: Geneticin; GFP: Green fluorescent protein; HIRA: Histone cell cycle regulation defective homologue A; HU: Hydroxyurea; IR: Ionising radiation; Kan: Kanamycin; Leu: Leucine; M phase: Mitosis; MCM: Mini-chromosome maintenance; mRNA: Messenger ribonucleic acid; NAT: Nourseothricin; OD: Optical density measured; ORF: Open reading frame; ORC: Origin recognition complex; PCNA: Proliferating cell nuclear antigen; PCR: Polymerase chain reaction; Pol: Polymerase;

PVDF: Polyvinylidene difluoride; Rad: Radiation; RFC: Replication factor complex; RNA: Ribonucleic acid; RPA: Replication protein A; RT-QPCR: Reverse transcriptase quantitative PCR; S. cerevisiae: Saccharomyces cerevisiae; S. pombe: Schizosaccharomyces pombe; S-phase: Synthesis phase; SDS: Sodium dodecyl sulphate; SDS-PAGE: Sodium dodecyl sulphate polyacrylamide gel electrophoresis; ssDNA: Single strand DNA; SWI/SNF: Switch/sucrose nonfermentable; T: Thymine; Top: Topoisomerase; Ura: Uracil; ura4: Gene encoding dihydroorotase (involved in the de novo biosynthesis of pyrimidines); v/v: Volume for volume; wt: Wild-type; YES: Yeast extract with supplements
\end{abstract}

\section{Acknowledgements}

Not applicable.

\section{Authors' contributions}

The work was carried out by HAE during the period of study for the degree of doctor of philosophy under the supervision of CP. No other entities have contributed to this study or research. All the laboratory work including preparation and results has been carried out by HAE. The analysis and interpretation of the results were carried out by HAE. The manuscript was written by HAE and revised by CP and HAE. All the authors have read and approved the manuscript.

\section{Funding}

This work was generously funded and supported by The North West Cancer Research fund, UK. The laboratory equipment, materials and stipends were provided for the duration of the study under the grant code CR918.

\section{Availability of data and materials}

All the data required for the processing of the conclusions are presented in the results section. Supporting data was included separately.

Ethics approval and consent to participate

Not applicable.

\section{Consent for publication}

Not applicable.

\section{Competing interests}

The author(s) declare that they have no competing interests.

Received: 27 November 2019 Accepted: 11 March 2020

Published online: 06 May 2020

\section{References}

1. Burgers P.M.J., Kunkel T.A. 2017, Eukaryotic DNA Replication Fork. Annu Rev Biochem. 20;86:417-438. Review.

2. Zhivotovsky B, Orrenius S (2010) Cell cycle and cell death in disease: past, present and future. J Intern Med. 268(5):395-409

3. Eyfjord J.E., Bodvarsdottir S.K. 2005, Genomic instability and cancer: networks involved in response to DNA damage. Mutat Res. 30;592(1-2):18-28. Review.

4. Negrini S, Gorgoulis VG, Halazonetis TD (2010) Genomic instability - an evolving hallmark of cancer. Nat Rev Mol Cell Biol 11(3):220-228 Review

5. Ciccia A., Elledge S.J. 2010, The DNA damage response: making it safe to play with knives. Mol Cell. 22;40(2):179-204. Review.

6. Macheret $M$, Halazonetis TD (2015) DNA replication stress as a hallmark of cancer. Annu Rev Pathol 10:425-448 Review

7. Bell S.P., Stillman B. 1992, ATP-dependent recognition of eukaryotic origins of DNA replication by a multiprotein complex. Nature. 14;357(6374):128-134.

8. Dhar S.K., Delmolino L., Dutta A. 2001, Architecture of the human origin recognition complex. J Biol Chem. 3:276(31):29067-29071.

9. Evrin C, Clarke P, Zech J, Lurz R, Sun J, Uhle S, Li H, Stillman B, Speck C (2009) A double-hexameric MCM2-7 complex is loaded onto origin DNA during licensing of eukaryotic DNA replication. Proc Natl Acad Sci 106(48): 20240-20245

10. Fragkos M, Ganier O, Coulombe P, Méchali M (2015) DNA replication origin activation in space and time. Nat Rev Mol Cell Biol 16(6):360-374

11. Ticau S, Friedman LJ, Ivica NA, Gelles J, Bell SP (2015) Single-molecule studies of origin licensing reveal mechanisms ensuring bidirectional helicase loading. Cell 161(3):513-525

12. Takeda DY, Dutta A (2005) DNA replication and progression through S phase. Oncogene 24(17):2827-2843

13. Kelman Z. 1997, PCNA: structure, functions and interactions. Oncogene. 13; 14(6):629-640. Review.

14. Tanaka S, Araki H (2010) Regulation of the initiation step of DNA replication by cyclin-dependent kinases. Chromosoma 119(6):565-574

15. Yeeles J.T.P., Janska A., Early A., Diffley J.F. 2017, How the eukaryotic replisome Achieves Rapid and Efficient DNA Replication. Mol Cell. 5;65(1): 105-116.

16. Yeeles JT, Deegan TD, Janska A, Early A, Diffley JF (2015) Regulated eukaryotic DNA replication origin firing with purified proteins. Nature 519(7544):431-435

17. Warmerdam DO, Kanaar R (2010) Dealing with DNA damage: relationships between checkpoint and repair pathways. Mutat Res. 704(1-3):2-11 Review

18. Byun T.S., Pacek M., Yee M.C., Walter J.C., Cimprich KA 2005, Functional uncoupling of MCM helicase and DNA polymerase activities activates the ATR-dependent checkpoint. Genes Dev. 1;19(9):1040-1052.

19. Cimprich KA, Cortez D (2008) ATR: an essential regulator of genome integrity. Nat Rev Mol Cell Biol 9(8):616-627 Review

20. Carr A.M., Moudjou M., Bentley N.J., Hagan I.M. 1995, The chk1 pathway is required to prevent mitosis following cell-cycle arrest at 'start'. Curr Biol. 1;5(10):1179-1190

21. Sanjiv K., Hagenkort A., Calderón-Montaño J.M., Koolmeister T., Reaper P.M., Mortusewicz O., Jacques S.A., Kuiper R.V., Schultz N., Scobie M., Charlton P.A., Pollard J.R., Berglund U.W., Altun M., Helleday T. 2016, Cancer-Specific Synthetic Lethality between ATR and CHK1 Kinase Activities. Cell Rep. 20;17(12):3407-3416.

22. Greenfeder SA, Newlon CS (1992) Replication forks pause at yeast centromeres. Mol Cell Biol 12(9):4056-4066 
23. Ivessa AS, Lenzmeier BA, Bessler JB, Goudsouzian LK, Schnakenberg SL, Zakian VA (2003) The Saccharomyces cerevisiae helicase Rrm3p facilitates replication past nonhistone protein-DNA complexes. Mol Cell 12(6):15251536

24. Caspari T, Carr AM (1999) DNA structure checkpoint pathways in Schizosaccharomyces pombe. Biochimie 81(1-2):173-181 Review

25. Zeng Y, Piwnica-Worms H (1999) DNA damage and replication checkpoints in fission yeast require nuclear exclusion of the Cdc25 phosphatase via 143-3 binding. Mol Cell Biol. 19(11):7410-7419

26. Bentley NJ, Holtzman DA, Flaggs G, Keegan KS, DeMaggio A, Ford JC, Hoekstra M, Carr AM (1996) The Schizosaccharomyces pombe rad3 checkpoint gene. EMBO J 15(23):6641-6651

27. Chapman CR, Evans ST, Carr AM, Enoch T (1999) Requirement of sequences outside the conserved kinase domain of fission yeast Rad3p for checkpoint control. Mol Biol Cell 10(10):3223-3238

28. Van C., Yan S., Michael W.M., Waga S., Cimprich K.A. 2010, Continued primer synthesis at stalled replication forks contributes to checkpoint activation. J Cell Biol. 19;189(2):233-246.

29. Bermudez V.P., Lindsey-Boltz L.A., Cesare A.J., Maniwa Y., Griffith J.D., Hurwitz J., Sancar A. 2003, Loading of the human 9-1-1 checkpoint complex onto DNA by the checkpoint clamp loader hRad17-replication factor C complex in vitro. Proc Natl Acad Sci U S A. 18;100(4):1633-1638.

30. Xu Y.J., Davenport M., Kelly T.J. 2006, Two-stage mechanism for activation of the DNA replication checkpoint kinase Cds1 in fission yeast. Genes Dev. 15;20(8):990-1003.

31. Yue M., Singh A., Wang Z., Xu Y.J. 2011, The phosphorylation network for efficient activation of the DNA replication checkpoint in fission yeast. J Biol Chem. 1;286(26):22864-22874.

32. de Bruin R.A., Wittenberg C. 2009, All eukaryotes: before turning off G1-S transcription, please check your DNA. Cell Cycle. 15;8(2):214-217. Review.

33. Caetano C., Klier S., de Bruin R.A. 2011, Phosphorylation of the MBF repressor Yox1p by the DNA replication checkpoint keeps the G1/S cellcycle transcriptional program active. PLoS One. 16;6(2):e17211.

34. Jeon Y., Ko E., Lee K.Y., Ko M.J., Park S.Y., Kang J., Jeon C.H., Lee H., Hwang D. S. 2011, TopBP1 deficiency causes an early embryonic lethality and induces cellular senescence in primary cells. J Biol Chem. 18;286(7):5414-5422.

35. Yamamoto RR, Axton JM, Yamamoto Y, Saunders RD, Glover DM, Henderson DS (2000) The Drosophila mus101 gene, which links DNA repair, replication and condensation of heterochromatin in mitosis, encodes a protein with seven BRCA1 C-terminus domains. Genetics 156(2):711-721

36. Enoch T, Carr AM, Nurse P (1992) Fission yeast genes involved in coupling mitosis to completion of DNA replication. Genes Dev 6(11):2035-2046

37. Enoch T, Nurse $P$ (1990) Mutation of fission yeast cell cycle control genes abolishes dependence of mitosis on DNA replication. Cell 60(4):665-673

38. Enoch T., Nurse P. 1991, Coupling M phase and S phase: controls maintaining the dependence of mitosis on chromosome replication. Cell. 14;65(6):921-923. Review.

39. Saka Y., Yanagida M. 1993, Fission yeast cut5+, required for S phase onset and $\mathrm{M}$ phase restraint, is identical to the radiation-damage repair gene rad4+. Cell. 30;74(2):383-393.

40. Saka Y., Fantes P., Sutani T., Mclnerny C., Creanor J., Yanagida M. 1994, Fission yeast cut 5 links nuclear chromatin and $M$ phase regulator in the replication checkpoint control. EMBO J. 15;13(22):5319-5329.

41. Sheldrick KS, Carr AM (1993) Feedback controls and G2 checkpoints: fission yeast as a model system. Bioessays 15(12):775-782 Review

42. Samejima I, Matsumoto T, Nakaseko Y, Beach D, Yanagida M (1993) Identification of seven new cut genes involved in Schizosaccharomyces pombe mitosis. J Cell Sci 105(Pt 1):135-143

43. McFarlane RJ, Carr AM, Price C (1997) Characterisation of the Schizosaccharomyces pombe rad4/cut5 mutant phenotypes: dissection of DNA replication and G2 checkpoint control function. Mol Gen Genet 255(3):332-340

44. Ransom M, Dennehey BK, Tyler JK (2010) Chaperoning histones during DNA replication and repair. Cell 140:183-195

45. Eitoku M, Sato L, Senda T, Horikoshi M (2008) Histone chaperones: 30 years from isolation to elucidation of the mechanisms of nucleosome assembly and disassembly. Cell Mol Life Sci 65(3):414-444 Review

46. Prochasson P., Florens L., Swanson S.K., Washburn M.P., Workman J.L. 2005, The HIR corepressor complex binds to nucleosomes generating a distinct
protein/DNA complex resistant to remodeling by SWI/SNF. Genes Dev. 1; 19(21):2534-2539.

47. Lee BS, Grewal SI, Klar AJ (2004) Biochemical interactions between proteins and mat1 cis-acting sequences required for imprinting in fission yeast. Mol Cell Biol. 24(22):9813-9822

48. Noguchi E, Noguchi C, McDonald WH, Yates JR 3rd, Russell P (2004) Swi1 and Swi3 are components of a replication fork protection complex in fission yeast. Mol Cell Biol 24(19):8342-8355

49. McFarlane R.J., Mian S., Dalgaard J.Z. 2010, The many facets of the Tim-Tipin protein families' roles in chromosome biology. Cell Cycle. 15:9(4):700-705.

50. Noguchi E, Noguchi C, Du LL, Russell P (2003) Swi1 prevents replication fork collapse and controls checkpoint kinase Cds1. Mol Cell Biol 23(21):78617874

51. Shimmoto M, Matsumoto S, Odagiri Y, Noguchi E, Russell P, Masai H (2009) Interactions between Swi1-Swi3, Mrc1 and S phase kinase, Hsk1 may regulate cellular responses to stalled replication forks in fission yeast. Genes Cells 14(6):669-682

52. Dalgaard J.Z., Klar A.J. 2000, swi1 and swi3 perform imprinting, pausing, and termination of DNA replication in S. pombe. Cell. 15;102(6):745-751.

53. Alcasabas AA, Osborn AJ, Bachant J, Hu F, Werler PJ, Bousset K, Furuya K, Diffley JF, Carr AM, Elledge SJ (2001) Mrc1 transduces signals of DNA replication stress to activate Rad53. Nat Cell Biol 3(11):958-965

54. Chini C.C., Chen J. 2003, Human claspin is required for replication checkpoint control. J Biol Chem. 8;278(32):30057-30062.

55. Kumagai A, Dunphy WG (2000) Claspin, a novel protein required for the activation of Chk1 during a DNA replication checkpoint response in Xenopus egg extracts. Mol Cell 6(4):839-849

56. Tanaka K, Russell P (2001) Mrc1 channels the DNA replication arrest signal to checkpoint kinase Cds1. Nat Cell Biol 3(11):966-972

57. Hodgson B, Calzada A, Labib K (2007) Mrc1 and Tof1 regulate DNA replication forks in different ways during normal $S$ phase. Mol Biol Cell 18(10):3894-3902

58. Petermann E, Helleday T, Caldecott KW (2008) Claspin promotes normal replication fork rates in human cells. Mol Biol Cell 19(6):2373-2378

59. Szyjka S.J., Viggiani C.J., Aparicio O.M. 2005, Mrc1 is required for normal progression of replication forks throughout chromatin in S. cerevisiae. Mol Cell. 2;19(5):691-697.

60. Tourrière H., Versini G., Cordón-Preciado V., Alabert C., Pasero P. 2005, Mrc1 and Tof 1 promote replication fork progression and recovery independently of Rad53. Mol Cell. 2;19(5):699-706.

61. Noguchi C, Rapp JB, Skorobogatko W, Bailey LD, Noguchi E (2012) Swi1 associates with chromatin through the DDT domain and recruits Swi3 to preserve genomic integrity. PLoS One 7(8):e43988

62. Hayano M, Kanoh Y, Matsumoto S, Masai H (2011) Mrc1 marks early-firing origins and coordinates timing and efficiency of initiation in fission yeast. Mol Cell Biol 31(12):2380-2391

63. Zhao H., Russell P. 2004, DNA binding domain in the replication checkpoint protein Mrc1 of Schizosaccharomyces pombe. J Biol Chem. 17;279(51): 53023-53027.

64. Tanaka S., Tak Y.S., Araki H. 2007, The role of CDK in the initiation step of DNA replication in eukaryotes. Cell Div. 5;2:16.

65. Katou Y., Kanoh Y., Bando M., Noguchi H., Tanaka H., Ashikari T., Sugimoto K. Shirahige K. 2003, S-phase checkpoint proteins Tof1 and Mrc1 form a stable replication-pausing complex. Nature. 28;424(6952):1078-1083.

66. Kim DU, Hayles J, Kim D, Wood V, Park HO, Won M, Yoo HS, Duhig T, Nam M, Palmer G, Han S, Jeffery L, Baek ST, Lee H, Shim YS, Lee M, Kim L, Heo KS, Noh EJ, Lee AR, Jang YJ, Chung KS, Choi SJ, Park JY, Park Y, Kim HM, Park SK, Park HJ, Kang EJ, Kim HB, Kang HS, Park HM, Kim K, Song K, Song KB, Nurse P, Hoe $\mathrm{KL}$ (2010) Analysis of a genome-wide set of gene deletions in the fission yeast Schizosaccharomyces pombe. Nat Biotechnol 28(6):617-623

67. Okazaki K., Okazaki N., Kume K., Jinno S., Tanaka K., Okayama H. 1990, Highfrequency transformation method and library transducing vectors for cloning mammalian cDNAs by trans-complementation of Schizosaccharomyces pombe. Nucleic Acids Res. 25;18(22):6485-6489.

68. Hagan IM, Hyams JS (1988) The use of cell division cycle mutants to investigate the control of microtubule distribution in the fission yeast Schizosaccharomyces pombe. J Cell Sci 89(Pt 3):343-357

69. Burnette WN (1981) "Western blotting": electrophoretic transfer of proteins from sodium dodecyl sulfate--polyacrylamide gels to unmodified nitrocellulose and radiographic detection with antibody and radioiodinated protein A. Anal Biochem 112(2):195-203 
70. Fennessy D., Grallert A., Krapp A., Cokoja A., Bridge A.J., Petersen J., Patel A., Tallada V.A., Boke E., Hodgson B., Simanis V., Hagan I.M. 2014, Extending the Schizosaccharomyces pombe molecular genetic toolbox. PLoS One. 21;9(5): e97683.

71. Sabatinos SA, Green MD, Forsburg SL (2012) Continued DNA synthesis in replication checkpoint mutants leads to fork collapse. Mol Cell Biol 32(24):4986-4997

72. Anderson HE, Wardle J, Korkut SV, Murton HE, López-Maury L, Bähler J, Whitehall SK (2009) The fission yeast HIRA histone chaperone is required for promoter silencing and the suppression of cryptic antisense transcripts. Mol Cell Biol 29(18):5158-5167

73. Calzada A., Hodgson B., Kanemaki M., Bueno A., Labib K. 2005, Molecular anatomy and regulation of a stable replisome at a paused eukaryotic DNA replication fork. Genes Dev. 15;19(16):1905-1919.

74. Lambert S., Froget B., Carr A.M. 2007, Arrested replication fork processing: interplay between checkpoints and recombination. DNA Repair (Amst). 1; 6(7):1042-1061. Review.

75. Lambert S., Watson A., Sheedy D.M., Martin B., Carr A.M. 2005, Gross chromosomal rearrangements and elevated recombination at an inducible site-specific replication fork barrier. Cell. 3;121(5):689-702.

\section{Publisher's Note}

Springer Nature remains neutral with regard to jurisdictional claims in published maps and institutional affiliations.

\section{Submit your manuscript to a SpringerOpen ${ }^{\circ}$ journal and benefit from:}

- Convenient online submission

- Rigorous peer review

- Open access: articles freely available online

High visibility within the field

- Retaining the copyright to your article

Submit your next manuscript at $\boldsymbol{\nabla}$ springeropen.com 